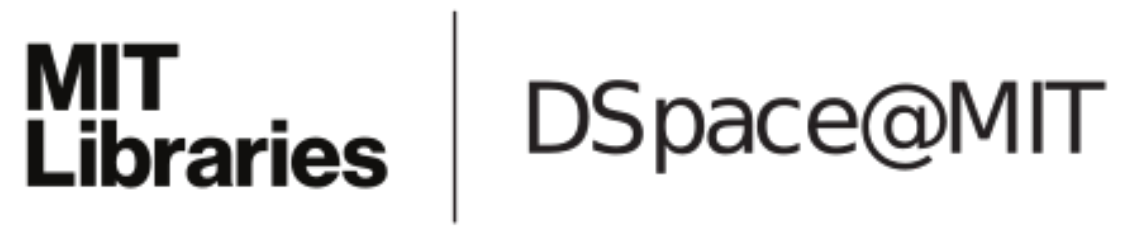

MIT Open Access Articles

A review of cermet-based spectrally selective solar absorbers

The MIT Faculty has made this article openly available. Please share how this access benefits you. Your story matters.

Citation: Cao, Feng, Kenneth McEnaney, Gang Chen, and Zhifeng Ren. "A Review of CermetBased Spectrally Selective Solar Absorbers." Energy Environ. Sci. 7, no. 5 (2014): 1615.

As Published: http://dx.doi.org/10.1039/c3ee43825b

Publisher: Royal Society of Chemistry

Persistent URL: http://hdl.handle.net/1721.1/99729

Version: Author's final manuscript: final author's manuscript post peer review, without publisher's formatting or copy editing

Terms of use: Creative Commons Attribution-Noncommercial-Share Alike 


\title{
A Review of Cermet-based Spectrally Selective Solar Absorbers
}

\author{
Feng Cao, ${ }^{\mathrm{a}}$ Kenneth McEnaney, ${ }^{\mathrm{b}}$ Gang Chen, ${ }^{* \mathrm{~b}}$ and Zhifeng Ren ${ }^{* \mathrm{a}}$ \\ ${ }^{a}$ Department of Physics and TcSUH, University of Houston, Houston, Texas 77204, USA \\ ${ }^{b}$ Department of Mechanical Engineering, Massachusetts Institute of Technology, Cambridge, Massachusetts \\ 02139, USA
}

To whom correspondence should be addressed, gchen2@mit.edu, zren@uh.edu

\begin{abstract}
Spectrally-selective solar absorbers harvest solar energy in the form of heat. Solar absorbers using cermet-based coatings demonstrate a high absorptance of the solar spectrum and a low emittance in the infrared (IR) regime. Extensive work has been done to optimize cermet-based solar absorbers to achieve high performance by exploring different cermet (ceramic-metal composite) materials and film configurations through different preparation techniques such as electrodeposition, sputtering, pulsed laser deposition, and solution-based methods. In this article, we review the progress of cermet-based spectrally-selective absorbers with high solar absorptance and low thermal emittance, such as $\mathrm{Cr}_{2} \mathrm{O}_{3}, \mathrm{Al}_{2} \mathrm{O}_{3}, \mathrm{AlN}, \mathrm{SiO}_{2}$, and $\mathrm{ZrO}_{2}$ based cermets as absorption layers. We also present an outlook for cermet-based spectrally-selective absorbers with high thermal stability and high conversion efficiency from sunlight to heat.
\end{abstract}

\begin{tabular}{|ll}
\hline \multicolumn{2}{l}{ Nomenclature } \\
$\alpha_{s}$ & Solar absorptance \\
$\varepsilon_{\lambda}^{\prime}$ & Spectral directional emittance \\
$\varepsilon_{t}$ & Thermal emittance \\
$\eta_{a b s}$ & Absorber efficiency \\
$\sigma_{s b}$ & Stefan-Boltzmann constant \\
$\mathrm{H}_{\mathrm{abs}}$ & Incident solar flux \\
$\mathrm{h}_{\mathrm{conv}}$ & Convective heat transfer coefficient \\
$I_{b \lambda}$ & Spectral blackbody intensity \\
$\mathrm{q}_{\mathrm{c}}$ & Waste heat
\end{tabular}




\begin{tabular}{|ll|}
\hline $\mathrm{q}_{\text {conv }}$ & Convective loss \\
$\mathrm{q}_{\mathrm{h}}$ & Heat flux \\
$\mathrm{q}_{\mathrm{rad}}$ & Radiative loss \\
$\mathrm{S}$ & Incident solar intensity \\
AM & Air mass \\
ARC & Anti-reflection coating \\
CSP & Concentrated solar power \\
CVD & Chemical vapor deposition \\
DC & Direct current \\
FTIR & Fourier transform infrared spectroscopy \\
HMVF & High metal volume fraction \\
IR & Infrared \\
LHL & L: low metal fraction in cermet; H: high metal fraction in cermet \\
LMVF & Low metal volume fraction \\
MNS & Molybdenum-coated nickel-plated stainless steel \\
PV & Photovoltaics \\
PVD & Physical vapor deposition \\
RF & Radio frequency \\
SS & Stainless steel \\
STEG & Solar thermoelectric generators \\
STPV & Solar thermophotovoltaics \\
TISS & Thickness-insensitive spectrally selective \\
TSSS & Thickness-sensitive spectrally selective \\
UV & Ultraviolet \\
XRD & X-ray diffraction \\
\hline
\end{tabular}

\section{Introduction}

The drive to replace fossil fuels with renewable energy sources such as solar and wind was accelerated by the energy crisis of the $1970 \mathrm{~s}^{1}$. Solar energy is abundant, striking the earth at a rate of 90,000 TW, which is 5,000 times our current global power consumption ${ }^{2}$. Generally there are two routes for harvesting solar energy: photovoltaics $(\mathrm{PV})^{3}$ and thermal processes. Photovoltaic conversion is the most widespread solar-to-electricity technology, with over $100 \mathrm{GW}$ installed to date $^{4}$. Thermal processes encompass a wide variety of technologies, all of which begin by converting the incident sunlight to heat. This heat can be converted to electricity, as is currently done in concentrated solar power (CSP) plants via a Rankine or combined cycle ${ }^{5}$, solar 
thermoelectric generators (STEG) $)^{6}$, and solar thermophotovoltaics (STPV ${ }^{7,8}$. Currently there are $3 \mathrm{GW}$ of installed and under-construction CSP plants in the world, but STEGs and STPV have yet to be commercialized. Solar thermal energy, or the waste heat from the aforementioned solar-toelectricity processes, can also be used for heating or cooling. Nearly $300 \mathrm{GW}$ of solar thermal heat or hot water systems have been installed worldwide ${ }^{7}$.

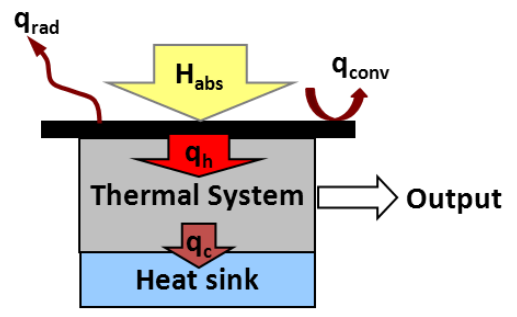

Fig. 1. A typical solar thermal energy conversion system. Sunlight incident on the absorber $\left(\mathrm{H}_{\mathrm{abs}}\right)$ is converted to a heat flux $\left(\mathrm{q}_{\mathrm{h}}\right)$ and delivered to the thermal system, where the desired output (work, electricity, heat, cooling, etc.) is produced. Waste heat $\left(\mathrm{q}_{\mathrm{c}}\right)$ may be generated in the process and rejected to a heat sink. Radiative ( $\mathrm{q}_{\mathrm{rad}}$ ) and convective $\left(\mathrm{q}_{\text {conv }}\right)$ losses at the surface reduce the potential output of the system.

A schematic of a typical solar thermal to electrical energy conversion system is shown in Fig. 1. In such solar thermal technologies, the sunlight is absorbed as heat at the absorber. This absorber must strongly absorb the sunlight, while ideally losing little heat to the environment via convection and radiation. An absorber which has strong solar absorptance and low infrared (IR) emittance is called a spectrally-selective absorber ${ }^{9}{ }^{10}$. In this review, we focus on spectrallyselective absorbers based on cermets, which are mixtures of ceramics and metals. When integrated with an anti-reflection coating (ARC) and an IR-reflective base layer (either an intrinsically IRreflecting substrate or an IR-reflective coating on a substrate), cermet-based coatings (Fig. 2) can be very effective spectrally-selective absorbers. 


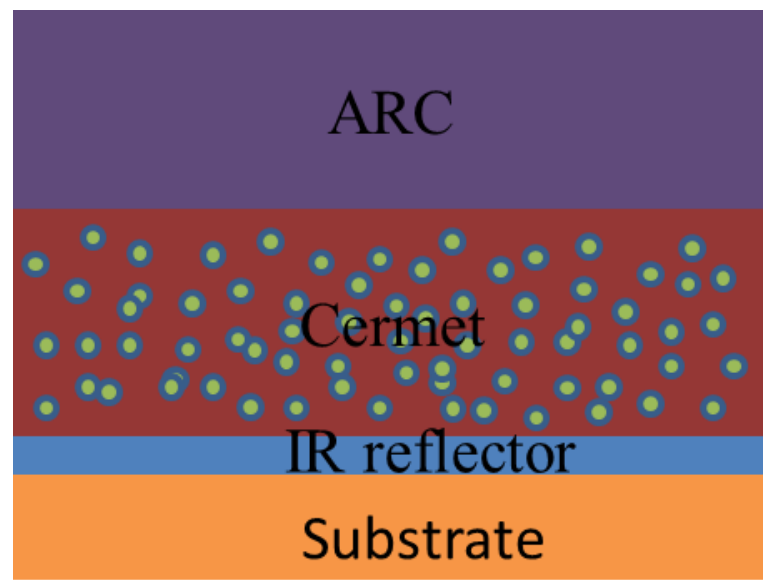

Fig. 2. Schematic representation of a cermet-based spectrally-selective absorber. The anti-reflection coating (ARC) reduces solar reflection off the surface; the cermet provides selective absorption; and the IR reflector (typically $\mathrm{Cu}, \mathrm{Al}, \mathrm{Mo}$, or other metal with low intrinsic emissivity) reduces radiation losses. The substrate is usually metal (to conduct heat well) or glass (for lower cost). The cermet comprises a dielectric host (dark red) with metal particle inclusions (circles).

In this review, we begin by summarizing the requirements for solar selectivity, as well as the metrics for evaluating absorbers. We then review the preparation techniques, materials, and performance of cermet-based spectrally-selective absorbers. Finally we present the future outlook for cermet-based absorbers.

\section{Selective Absorber Theory}

Absorbers must efficiently convert a solar flux into heat, and deliver that heat to the thermal system (Fig. 1). The efficiency of the conversion from solar irradiance at the absorber, $H_{a b s}$, to a heat flux delivered to the thermal system, $q_{h}$, is defined as the absorber efficiency, $\eta_{a b s}$ :

$$
\eta_{a b s}=\frac{q_{h}}{H_{a b s}}=\alpha_{s}-\varepsilon_{t} \frac{\sigma_{s b}\left(T_{h}^{4}-T_{a m b}^{4}\right)}{H_{a b s}}-\frac{h_{c o n v}\left(T_{h}-T_{a m b}\right)}{H_{a b s}}
$$

where $\sigma_{s b}$ is the Stefan-Boltzmann constant, $T_{h}$ is the absorber temperature, $T_{a m b}$ is the temperature of the environment, and $h_{\text {conv }}$ is the convective heat transfer coefficient. The solar absorptance, $\alpha_{s}$, is defined as: 


$$
\alpha_{S}=\frac{\int_{0}^{\infty} \int_{0}^{2 \pi} \int_{0}^{\pi / 2} \varepsilon^{\prime} \lambda(\lambda, \phi, \theta) S(\lambda, \phi, \theta) \cos \theta \sin \theta d \lambda d \phi d \theta}{\int_{0}^{\infty} \int_{0}^{2 \pi} \int_{0}^{\pi / 2} S(\lambda, \phi, \theta) \cos \theta \sin \theta d \lambda d \phi d \theta}
$$

where $\lambda$ is the wavelength of radiation, $\phi$ is the azimuthal angle, $\theta$ is the polar angle, $\varepsilon^{\prime}{ }_{\lambda}$ is the spectral directional emittance at the operational temperature, and $\mathrm{S}$ is the incident solar intensity at the absorber. The numerator of this equation is the total absorbed solar energy; the denominator is the incident solar flux $H_{a b s}$.

The thermal emittance, $\varepsilon_{t}$, is defined as:

$$
\varepsilon_{t}=\frac{\int_{0}^{\infty} \int_{0}^{2 \pi} \int_{0}^{\pi / 2} \varepsilon^{\prime} \lambda(\lambda, \phi, \theta) I_{b \lambda}(\lambda, \phi, \theta) \cos \theta \sin \theta d \lambda d \phi d \theta}{\int_{0}^{\infty} \int_{0}^{2 \pi} \int_{0}^{\pi / 2} I_{b \lambda}(\lambda, \phi, \theta) \cos \theta \sin \theta d \lambda d \phi d \theta}
$$

where $I_{b \lambda}$ is the blackbody intensity given by Planck's formula. Although the formulae for the solar absorptance and the thermal emittance look very similar, the fact that the solar intensity and the blackbody intensity for moderate-temperature surfaces are distributed over different wavelength regimes (Fig. 3) can be utilized to design selective absorbers. By having a large emittance in the solar wavelengths and a small emittance in the infrared, absorbers can have high solar absorptance and low thermal emittance, thus resulting in a high absorber efficiency. Using spectrally-selective surfaces as solar absorbers was first proposed by Tabor in $1955^{11}$. A similar strategy can be pursued to take advantage of the differences in angular distribution between the solar spectrum and the (isotropic) blackbody spectrum ${ }^{12}$, but that concept is relatively new and will not be discussed in this work. 


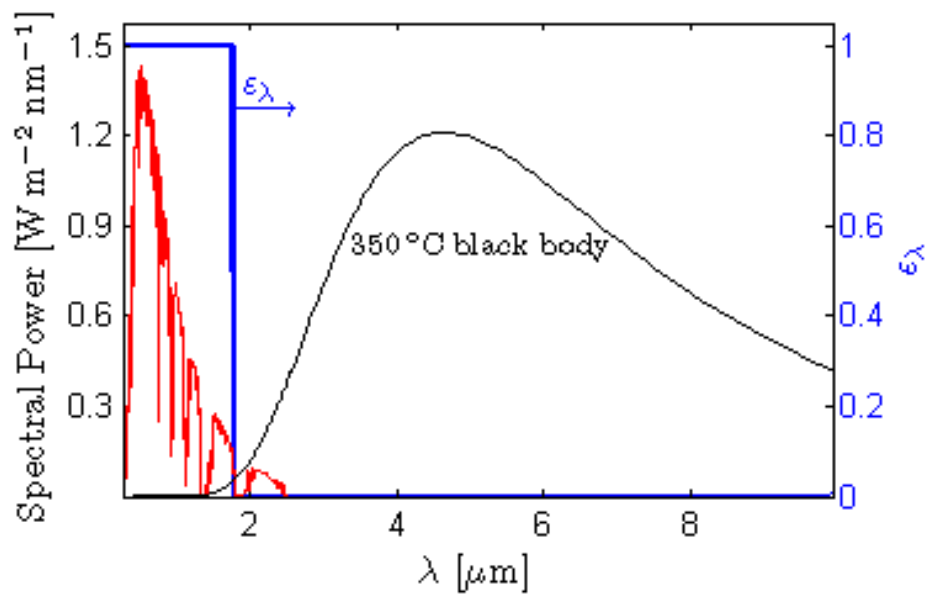

Fig. 3. Unconcentrated AM 1.5 Direct + Circumsolar spectrum (red, left axes) and spectrum of $350{ }^{\circ} \mathrm{C}$ blackbody (black, left axes). The ideal emittance profile (blue, right axes) transitions from 1 to 0 where the spectra cross, in this case at $1.8 \mu \mathrm{m}$

An ideal spectrally-selective absorber has an emittance of 1 at short wavelengths and 0 at long wavelengths, with a sharp transition between the two regimes. The wavelength where the transition occurs, $\lambda_{t}$, should be where the blackbody intensity begins to exceed the solar intensity ${ }^{13}$ (Fig. 3). As represented in Fig, 3, the spectral intensity of a $350{ }^{\circ} \mathrm{C}$ blackbody exceeds the AM1.5 Direct + Circumsolar solar spectrum beginning at $1.8 \mu \mathrm{m}$. For higher-temperature absorbers, the ideal transition wavelength will shift to shorter wavelengths; at higher concentrations, the ideal transition wavelength will shift to longer wavelengths. The ideal transition wavelength is a function of both concentration and temperature (Fig. 4). The ideal transition wavelength is not a smooth function of temperature because the solar spectrum is not a smooth function; the crossover point will not occur at wavelengths where the solar spectrum is essentially zero due to atmospheric absorption. For space-based applications outside of the earth's atmosphere, these gaps would not exist; the optimal transition wavelength would be a smooth function of the hot-side temperature and the optical concentration. 


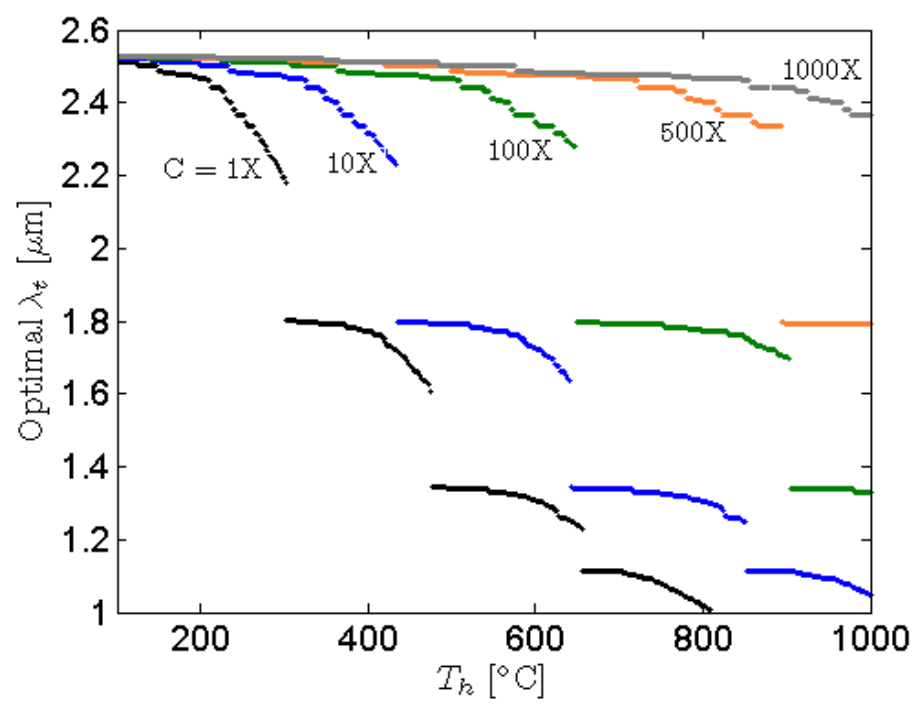

Fig. 4. Spectrally-selective absorber optimal transition wavelength as a function of hot-side temperature for five different optical concentrations ${ }^{13}$. The discrete jumps result from the fact that the solar spectrum reaching the earth drops to nearly zero around $1.4 \mu \mathrm{m}$ and $1.8 \mu \mathrm{m}$ (due to atmospheric absorption), and thus the blackbody spectrum cannot intersect the solar spectrum in these regions.

The ideal emittance profile drops from 1 to 0 at the transition wavelength. However, it is more realistic to assume that an emittance profile would drop down to a small but non-zero value after the transition wavelength. It is important to realize that this correction does not change the ideal transition wavelength in figure 4: the two spectra will cross at the same place regardless of the emittance profile. However, finite long-wavelength emittance does have a strong effect on the absorber efficiency as defined in equation (1). Even a long-wavelength emittance of only 0.01 drastically reduces the efficiency for high-temperature, low concentration applications. Because of this, the transition wavelengths that are worth investigating for terrestrial solar thermal applications are those between 1.6 and $1.8 \mu \mathrm{m}$, and between 2.2 and $2.5 \mu \mathrm{m}$.

While figure 4 gives a target transition wavelength for a spectrally-selective absorber for a given application (temperature and incident flux), it is also worthwhile to know the relative importance of the solar absorptance and thermal emittance on the absorber efficiency when evaluating real spectrally-selective absorbers. If the surface is enclosed in a vacuum, the convective 
losses go to zero and the last term in the absorber efficiency equation (Eq. (1)) disappears. This equation can then be simplified as:

$$
\eta_{a b s}=\frac{q_{h}}{H_{a b s}}=\alpha_{s}-w \varepsilon_{t}
$$

where $w$, the weighting factor between the solar absorptance and thermal emittance, is:

$$
w=\frac{\sigma_{s b}\left(T_{h}^{4}-T_{a m b}^{4}\right)}{H_{a b s}}
$$

When $w$ is close to 1 , the solar absorptance and thermal emittance are equally important for absorber efficiency. When $w$ is much less than 1, the solar absorptance is the critical parameter. The weighting factor as a function of incident flux is plotted in Fig. 5. A typical domestic hot water heater operates near $1 \mathrm{~kW} / \mathrm{m}^{2}$ ( 1 sun) at a temperature near $100{ }^{\circ} \mathrm{C}$; this yields a weighting factor of 0.7, which indicates that the thermal emittance is nearly as important as the solar absorptance. A linear fresnel CSP plant operating at 60 suns and $350{ }^{\circ} \mathrm{C}$ has a weighting factor of 0.14 , showing that an increase in solar absorptance of 0.01 produces a gain in efficiency equivalent to a reduction of thermal emittance of 0.07. Stirling-based parabolic dish CSP systems can reach fluxes exceeding $1000 \mathrm{~kW} / \mathrm{m}^{2}$ with operating temperatures reaching $700{ }^{\circ} \mathrm{C}$. Under such conditions, the weighting factor is less than 0.05 , showing that solar absorptance is the critical parameter to improve. The benefit of knowing the weighting factor for a given application is that it allows for rapid calculation of the absorber efficiency, which is the best metric for absorber thermal performance.

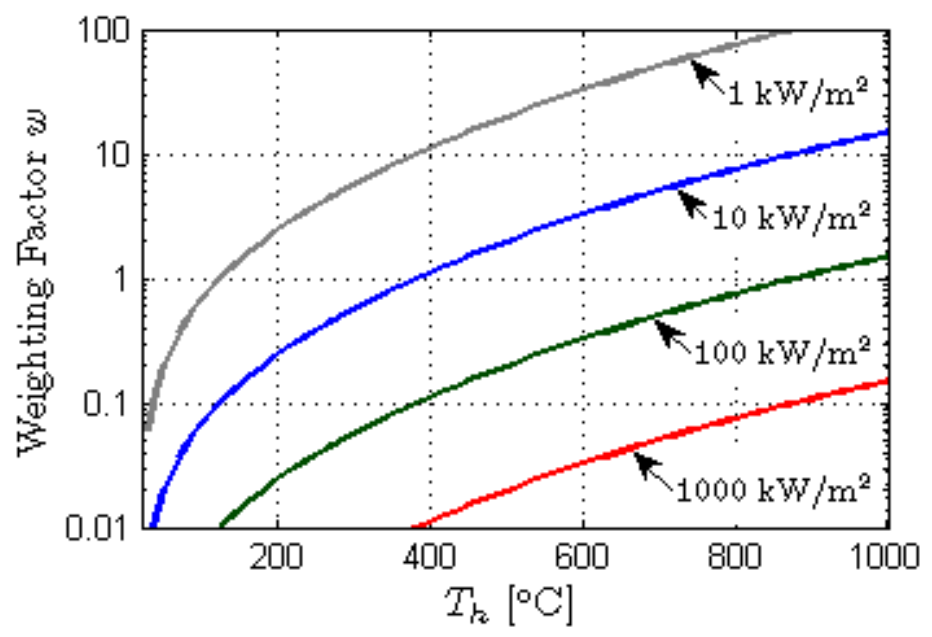


Fig. 5. The weighting factor as a function of surface temperature for four different incident solar fluxes. When the weighting factor is small, the absorber efficiency is most heavily influenced by the solar absorptance.

With this knowledge of the ideal transition wavelength as well as the relative importance of the solar absorptance versus the thermal emittance, we will review progress since 1955 on developing spectrally-selective absorbers.

Since the first studies on spectrally-selective coatings by Tabor and Gier in 1955 and after ${ }^{14-}$ ${ }^{16}$, investigations of various spectrally-selective absorbers have been carried out, such as black chrome coatings prepared by electrodeposition for solar hot water applications ${ }^{17-20}, \mathrm{Ni}-\mathrm{Al}_{2} \mathrm{O}_{3}$ cermet-based coatings prepared by sputtering and solution-chemical methods ${ }^{21-23}, \mathrm{Cr} / \mathrm{Cr}_{\mathrm{x}} \mathrm{O}_{\mathrm{y}} / \mathrm{Cr}_{2} \mathrm{O}_{3}$ multilayer absorber coatings ${ }^{24}$, thickness-sensitive spectrally selective (TSSS) paints including organic black carbon and inorganic $\mathrm{FeMnCuO}_{\mathrm{x}}$ pigment $^{25}$, and thickness-insensitive spectrally selective (TISS) paints ${ }^{26,27}$. Based on the configuration of coatings and the absorption mechanism, these spectrally-selective absorbers can be classified into six types ${ }^{9}:$ 1) intrinsically selective, 2) semiconductor-on-metal coatings, 3) multilayer stacks, 4) metal-dielectric (cermet) composites, 5) textured surfaces, and 6) selectively-transmitting coatings on blackbody-like absorbers. However, in practical absorbers not just one but several mechanisms are invoked to achieve better spectral selectivity, such as multilayer cermet-based absorbers which comprise multilayer stacks and metaldielectric composite coatings.

Cermet coatings have been extensively investigated and are now still extensively researched due to their high solar absorptance, low IR emittance, and good thermal stability for mid- and hightemperature applications such as concentrated solar power (CSP) systems and solar thermoelectric generators (STEGs). A cermet is a metal-dielectric composite in which metal is embedded in the dielectric matrix of an oxide, nitride, or oxynitride. A cermet should have ceramic characteristics in the visible spectrum and metallic properties in the IR. The coating thickness, constituents, and metal volume fraction in the matrix, as well as particle size, shape and orientation can affect how strongly the ceramic or metallic characteristics are expressed across the solar and IR spectra. Thicker coatings and smaller particle sizes are beneficial for high absorptance in the visible range. With an increase in particle radius, there is a shift of the visible absorption and scattering, resulting in lower 
absorption. Thermal emittance in the IR can be decreased by decreasing the coating thickness and increasing the metallic concentration. ${ }^{28}$

Though some researchers have reviewed the process of mid- and high-temperature solar selective absorber materials and physical vapor deposited (PVD) spectrally-selective coatings for

mid- and high-temperature solar thermal applications ${ }^{9}{ }^{29}$, there are few reports focused on cermetbased spectrally-selective solar absorbers. Herein we present a detailed overview of cermet-based spectrally-selective coatings and treatments. We discuss one by one the solar thermal performance of different dielectric materials such as $\mathrm{Cr}_{2} \mathrm{O}_{3}, \mathrm{Al}_{2} \mathrm{O}_{3}, \mathrm{AlN}, \mathrm{SiO}_{2}$, and other materials, and give an outlook for cermet-based spectrally-selective absorbers.

\section{Preparation of cermet-based solar absorbers}

Many methods such as electroplating, anodization, physical and chemical vapor deposition and solution-based fabrication have been utilized to prepare cermet-based spectrally-selective absorbers.

\subsection{Electroplating}

Electroplating is an electrolytic process in which a metal anode goes into an electrolyte as it is deposited on cathode. Electroplating has been employed to prepare cermet spectrally-selective absorbers, especially black chrome comprising 75 percent chromium and 25 percent chromium oxide, which has been utilized in mid-temperature $\left(\sim 300{ }^{\circ} \mathrm{C}\right)$ parabolic trough solar collector systems $^{30,31}$. During the deposition process, the plating current density, bath temperature, substrate, and plating time can affect the morphology and performance of the as-prepared film. There are still some issues about nonuniform film thickness, high thermal emittance, and the environmental concerns of electroplating.

\subsection{Anodizing}

Similar to electroplating, anodizing also employs an electrochemical reaction in a special electrolyte to produce a coating. It was first utilized to protect seaplane parts from corrosion. Anodizing of aluminum is done in a suitable electrolyte, such as an aqueous solution of sulfuric acid, and aluminum is used as the anode in which an electrolytic reaction of aluminum with oxygen generated from the electrolyte takes place, producing an $\mathrm{Al}_{2} \mathrm{O}_{3}$-based cermet. Titanium can also be 
anodized; the result is a coating whose color is dependent on the thickness of the deposited film. For aluminum, the color can be tuned by changing the preparation parameters such as time, temperature,

and current density ${ }^{32,33}$. Metallic dopants can be added during the anodization process to change the properties of the cermet.

\subsection{Evaporation}

Cermet films can also be created by the condensation of an evaporated material onto the substrate. In the process of thermal evaporation, the heating of material is carried out by a resistive heater or an electron beam. Various $\mathrm{Al}_{2} \mathrm{O}_{3}$ cermets $\left(\mathrm{Al}-\mathrm{Al}_{2} \mathrm{O}_{3}, \mathrm{Co}-\mathrm{Al}_{2} \mathrm{O}_{3}, \mathrm{Pt}-\mathrm{Al}_{2} \mathrm{O}_{3}, \mathrm{Cr}^{-} \mathrm{Al}_{2} \mathrm{O}_{3}\right)$ and black chrome were developed using this technique ${ }^{34-36}$.

\subsection{Chemical vapor deposition (CVD)}

In 1893, the first industrial exploitation of chemical vapor deposition was patented by de Lodyguine, who demonstrated a deposition of $\mathrm{W}$ onto carbon lamp filaments via the reaction of $\mathrm{WCl}_{6}$ and $\mathrm{H}_{2}$. CVD is the reaction of gaseous reactants on or near a substrate surface in a heated, lighted, or plasma-filled environment. It can also be used to deposit high-purity, high-performance films. Various kinds of materials, such as semiconductors ( $\left.\mathrm{Si}, \mathrm{Ge}, \mathrm{Si}_{1-\mathrm{x}} \mathrm{Ge}_{\mathrm{x}}\right)$, dielectrics $\left(\mathrm{Al}_{2} \mathrm{O}_{3}, \mathrm{SiC}\right.$, $\mathrm{TiN}, \mathrm{ZrO}_{2}$ ), and metal ( $\mathrm{Pt}, \mathrm{W}, \mathrm{Au}, \mathrm{Cu}$ ) films can be developed using $\mathrm{CVD}$. It can also be utilized to prepare solar selective surfaces, for instance, W-based metal oxide coatings used as a black metal spectrally-selective absorbers ${ }^{37,38}$.

\subsection{Sputtering}

Sputtering is a physical vapor deposition technique wherein a target material surface is eroded by particle bombardment and then condenses on a substrate. Sputtering can be used for large-area deposition. Many industrial applications, such as the deposition of metal films, semiconductor films, and antireflection coatings for optical applications, have been achieved using sputtering. Spectrally-selective solar absorbers have also been extensively developed by sputtering. Cr- $-\mathrm{Cr}_{2} \mathrm{O}_{3}$ cermets have been deposited by using $\mathrm{Cr}$ and $\mathrm{Cr}_{2} \mathrm{O}_{3}$ composite targets with radio frequency (RF) sputtering or using a single $\mathrm{Cr}$ target via reaction sputtering in $\mathrm{Ar}+\mathrm{O}_{2}$ gas flow $^{39}, 40$. Zhang et al. has deposited W-AlN, Mo-AlN, and stainless steel (SS)-AlN cermets by two-target DC 
sputtering $^{41,42}$. During the deposition of M-AlN cermet layers, both targets were run simultaneously in the mixture of $\mathrm{Ar}$ and $\mathrm{N}_{2}$.

\subsection{Solution-based method}

Various nanomaterials and ceramics have been fabricated by employing solution-based methods for many decades. In recent years, some spectrally-selective solar absorbers have been prepared by this route. Compared with other techniques, such as evaporation, CVD, and sputtering, the simplicity and low cost of solution-based processing allow it to be a possible candidate for large-scale deposition of spectrally-selective coatings. The biggest challenge is the preparation of a uniform and stable precursor containing as-designed metal ions. $\mathrm{Ni}-\mathrm{Al}_{2} \mathrm{O}_{3}$ cermet-based spectrallyselective coatings have been prepared in an aqueous solution with a chelating agent and a wetting agent ${ }^{43}$. Ni nanochains embedded in an $\mathrm{Al}_{2} \mathrm{O}_{3}$ matrix were synthesized by mixing the Ni nanochains (prepared by the reaction of $\mathrm{Ni}^{2+}$ with $\mathrm{N}_{2} \mathrm{H}_{4}$ ) with $\mathrm{Al}_{2} \mathrm{O}_{3} \mathrm{sol}^{44}$.

\section{Spectral selectivity of cermet-based absorbers}

Cermet-based spectrally-selective absorbers have potential for high-temperature applications (over $400{ }^{\circ} \mathrm{C}$ ). The preparation parameters and selective characteristics are summarized in Table 1. We discuss and review the performance of each kind of cermet-based absorber according to the dielectrics used.

Table. 1. Cermet-based spectrally-selective absorbers, sorted by host matrix. SS is stainless steel. Duration and temperature of stability tests are listed when reported. When noted with an asterisk, thermal emittance is extrapolated from room-temperature emittance data instead of measured at temperature.

\begin{tabular}{|c|ccccccc|}
\hline Matrix & $\begin{array}{c}\text { Metal } \\
\text { Inserts }\end{array}$ & Preparation & Substrate & Stability & $\begin{array}{c}\text { Solar } \\
\text { Absorptance }\end{array}$ & $\begin{array}{c}\text { Thermal } \\
\text { Emittance }\end{array}$ & Ref. \\
\hline \multirow{3}{*}{$\mathbf{C r}_{2} \mathbf{O}_{3}$} & $\mathrm{Cr}$ & Electroplating & Aluminum & --- & 0.868 & $\begin{array}{c}0.088^{*} \\
\left(121^{\circ} \mathrm{C}\right)\end{array}$ & 20 \\
& $\mathrm{Cr}$ & Electroplating & Copper & $300{ }^{\circ} \mathrm{C}$ & 0.93 & $\begin{array}{c}0.12 \\
\left(27^{\circ} \mathrm{C}\right)\end{array}$ & 19 \\
& $\mathrm{Cr}$ & Electroplating & Aluminum & $350{ }^{\circ} \mathrm{C}$ & 0.98 & $\begin{array}{c}0.2 \\
\left(27^{\circ} \mathrm{C}\right)\end{array}$ & 45
\end{tabular}




\begin{tabular}{|c|c|c|c|c|c|c|c|}
\hline & $\mathrm{Cr}$ & Electroplating & Nickel & $300{ }^{\circ} \mathrm{C}$ & 0.96 & $\begin{array}{c}0.25 \sim 0.35^{*} \\
\left(300^{\circ} \mathrm{C}\right)\end{array}$ & 17 \\
\hline & $\mathrm{Cr}$ & Sputtering & $\begin{array}{l}\text { Stainless } \\
\text { Steel }\end{array}$ & $300{ }^{\circ} \mathrm{C}$ & 0.92 & $\begin{array}{c}0.08^{*} \\
\left(121^{\circ} \mathrm{C}\right)\end{array}$ & 40 \\
\hline & $\mathrm{Cr}$ & Sputtering & Copper & --- & $0.90 \sim 0.94$ & $\begin{array}{l}0.04^{*} \\
\left(65^{\circ} \mathrm{C}\right)\end{array}$ & 39 \\
\hline & $\mathrm{Cr}$ & Sputtering & Copper & --- & 0.94 & $\begin{array}{c}0.06^{*} \\
\left(82^{\circ} \mathrm{C}\right)\end{array}$ & 46 \\
\hline & $\mathrm{Cr}$ & Sputtering & Optical slide & --- & $0.92 \sim 0.96$ & $\begin{array}{c}0.05 \sim 0.08^{*} \\
\left(100^{\circ} \mathrm{C}\right)\end{array}$ & 47 \\
\hline \multirow{12}{*}{$\mathrm{Al}_{2} \mathbf{O}_{3}$} & $\mathrm{Ni}$ & Anodizing & Aluminum & $\begin{array}{r}250^{\circ} \mathrm{C} \\
\text { in air }\end{array}$ & $0.90 \sim 0.96$ & $\begin{array}{c}0.06 \sim 0.46 \\
\left(100{ }^{\circ} \mathrm{C}\right)\end{array}$ & 49 \\
\hline & $\mathrm{Ni}$ & Evaporation & Fused-quartz & $\begin{array}{c}500^{\circ} \mathrm{C} \\
\text { in air }\end{array}$ & 0.94 & $\begin{array}{c}0.1 \\
\text { (estimated) }\end{array}$ & 23 \\
\hline & $\mathrm{Ni}$ & Sputtering & $\begin{array}{l}\text { Stainless } \\
\text { Steel }\end{array}$ & $\begin{array}{l}500{ }^{\circ} \mathrm{C} \\
\text { in air }\end{array}$ & 0.94 & $\begin{array}{c}0.07^{*} \\
\left(100^{\circ} \mathrm{C}\right)\end{array}$ & 22 \\
\hline & $\mathrm{Ni}$ & $\begin{array}{c}\text { Solution- } \\
\text { based method }\end{array}$ & Aluminum & --- & 0.93 & $\begin{array}{c}0.04^{*} \\
\left(100^{\circ} \mathrm{C}\right)\end{array}$ & 51 \\
\hline & $\mathrm{Ni}$ & $\begin{array}{c}\text { Solution- } \\
\text { based method }\end{array}$ & Aluminum & --- & 0.93 & $\begin{array}{c}0.03^{*} \\
\left(100^{\circ} \mathrm{C}\right)\end{array}$ & 52 \\
\hline & $\mathrm{Ni}$ & $\begin{array}{c}\text { Solution- } \\
\text { based method }\end{array}$ & Aluminum & $\begin{array}{c}300^{\circ} \mathrm{C} \\
\text { in air }\end{array}$ & 0.93 & $\begin{array}{c}0.05^{*} \\
\left(100^{\circ} \mathrm{C}\right)\end{array}$ & 43 \\
\hline & $\mathrm{Co}$ & Evaporation & Nickel & --- & 0.95 & $\begin{array}{c}0.1 \\
\left(100^{\circ} \mathrm{C}\right)\end{array}$ & 35 \\
\hline & $\mathrm{Ag}$ & Sputtering & Copper & $\begin{array}{c}400{ }^{\circ} \mathrm{C} \\
\text { in vacuum }\end{array}$ & 0.93 & $\begin{array}{c}0.04 \sim 0.05^{*} \\
\left(82^{\circ} \mathrm{C}\right)\end{array}$ & 55 \\
\hline & Mo & Sputtering & $\begin{array}{l}\text { Stainless } \\
\text { Steel }\end{array}$ & $\begin{array}{c}2 \mathrm{~h} @ 800{ }^{\circ} \mathrm{C} \\
\text { in vacuum }\end{array}$ & 0.92 & $\begin{array}{c}0.19 \\
\left(80^{\circ} \mathrm{C}\right)\end{array}$ & 56 \\
\hline & Mo & Sputtering & $\begin{array}{l}\text { Stainless } \\
\text { Steel }\end{array}$ & $\begin{array}{c}1 \mathrm{~h} @ 800{ }^{\circ} \mathrm{C} \text { in } \\
\text { vacuum }\end{array}$ & 0.92 & $\begin{array}{c}0.16 \\
\left(80^{\circ} \mathrm{C}\right)\end{array}$ & 57 \\
\hline & $\mathrm{W}$ & Sputtering & $\begin{array}{l}\text { Stainless } \\
\text { Steel }\end{array}$ & $\begin{array}{c}580{ }^{\circ} \mathrm{C} \\
\text { in vacuum }\end{array}$ & 0.939 & $\begin{array}{c}0.12^{*} \\
\left(400{ }^{\circ} \mathrm{C}\right)\end{array}$ & 58 \\
\hline & $\mathrm{Pt}$ & Evaporation & Quartz & --- & 0.98 & $\begin{array}{c}0.36^{*} \\
\left(200{ }^{\circ} \mathrm{C}\right) \\
\end{array}$ & 36 \\
\hline \multirow{5}{*}{ AlN } & $\mathrm{W}$ & Sputtering & Glass & $\begin{array}{c}500^{\circ} \mathrm{C} \\
\text { in vacuum }\end{array}$ & 0.939 & $\begin{array}{c}0.039 \\
\left(27^{\circ} \mathrm{C}\right)\end{array}$ & 60 \\
\hline & $\mathrm{W}$ & Sputtering & Glass & --- & 0.953 & $\begin{array}{l}0.051^{*} \\
\left(80^{\circ} \mathrm{C}\right)\end{array}$ & 41 \\
\hline & SS & Sputtering & Glass & $\begin{array}{c}500^{\circ} \mathrm{C} \\
\text { in vacuum }\end{array}$ & 0.933 & $\begin{array}{c}0.025 \\
\left(27^{\circ} \mathrm{C}\right)\end{array}$ & 61 \\
\hline & SS & Sputtering & Glass & --- & $0.94 \sim 0.95$ & $\begin{array}{c}0.04 \sim 0.05 \\
\left(27^{\circ} \mathrm{C}\right)\end{array}$ & 66 \\
\hline & $\mathrm{Al}$ & Sputtering & Aluminum & --- & 0.96 & --- & 68 \\
\hline
\end{tabular}




\begin{tabular}{|c|c|c|c|c|c|c|c|}
\hline & $\mathrm{Al}$ & Sputtering & Glass & --- & 0.92 & $\begin{array}{c}0.06^{*} \\
\left(100^{\circ} \mathrm{C}\right)\end{array}$ & 69 \\
\hline \multirow{7}{*}{$\mathrm{SiO}_{2}$} & $\mathrm{Cu}$ & Evaporation & Glass & $277^{\circ} \mathrm{C}$ & 0.93 & $\begin{array}{c}0.05 \\
\left(27^{\circ} \mathrm{C}\right)\end{array}$ & 72 \\
\hline & $\mathrm{Cu}$ & Evaporation & $\begin{array}{l}\text { Metal or } \\
\text { Glass }\end{array}$ & --- & 0.911 & $\begin{array}{c}0.0196^{*} \\
\left(50{ }^{\circ} \mathrm{C}\right)\end{array}$ & 34 \\
\hline & $\mathrm{Ni}$ & Evaporation & Quartz & $\begin{array}{c}500{ }^{\circ} \mathrm{C} \\
\text { in vacuum }\end{array}$ & 0.9 & $\begin{array}{c}0.07 \\
\left(100{ }^{\circ} \mathrm{C}\right)\end{array}$ & 73 \\
\hline & $\mathrm{Ni}$ & Sputtering & Aluminum & --- & 0.96 & $\begin{array}{c}0.14^{*} \\
\left(100^{\circ} \mathrm{C}\right)\end{array}$ & 75 \\
\hline & $\mathrm{Au}$ & Evaporation & Glass & --- & $0.88 \pm 0.01$ & $\begin{array}{l}0.014 \pm 0.005 \\
\quad\left(100{ }^{\circ} \mathrm{C}\right)\end{array}$ & 74 \\
\hline & Mo & Sputtering & $\begin{array}{l}\text { Stainless } \\
\text { Steel }\end{array}$ & $\begin{array}{c}580^{\circ} \mathrm{C} \\
\text { in vacuum }\end{array}$ & 0.94 & $\begin{array}{c}0.13^{*} \\
\left(580^{\circ} \mathrm{C}\right)\end{array}$ & 71 \\
\hline & Mo & Sputtering & Quartz & $\begin{array}{c}2 \mathrm{~h} @ 800{ }^{\circ} \mathrm{C} \\
\text { in vacuum }\end{array}$ & 0.95 & $\begin{array}{l}0.075^{*} \\
\left(80^{\circ} \mathrm{C}\right) \\
\end{array}$ & 70 \\
\hline \multirow{3}{*}{$\begin{array}{l}\text { NiS- } \\
\text { ZnS }\end{array}$} & \multirow{3}{*}{$\mathrm{Ni} / \mathrm{Zn}$} & \multirow{3}{*}{$\begin{array}{c}\text { Solution- } \\
\text { based method }\end{array}$} & $\begin{array}{l}\text { Galvanized } \\
\text { Iron }\end{array}$ & $\begin{array}{l}50 \mathrm{~h} \text { cycling } \\
100-200{ }^{\circ} \mathrm{C}\end{array}$ & 0.93 & $\begin{array}{c}0.08^{*} \\
\left(100^{\circ} \mathrm{C}\right)\end{array}$ & \\
\hline & & & $\begin{array}{l}\text { Zincated } \\
\text { Aluminium }\end{array}$ & $\begin{array}{l}24 \mathrm{~h} \text { cycling } \\
100-200^{\circ} \mathrm{C}\end{array}$ & 0.9 & $\begin{array}{c}0.14^{*} \\
\left(100^{\circ} \mathrm{C}\right)\end{array}$ & 76 \\
\hline & & & $\begin{array}{c}\text { Zinc } \\
\text { Electroplated } \\
\text { Aluminium }\end{array}$ & $\begin{array}{l}50 \mathrm{~h} \text { cycling } \\
100-200^{\circ} \mathrm{C}\end{array}$ & 0.94 & $\begin{array}{c}0.1^{*} \\
\left(100^{\circ} \mathrm{C}\right)\end{array}$ & \\
\hline $\mathrm{MoO}_{3}$ & Mo & $\begin{array}{c}\text { Solution- } \\
\text { based method }\end{array}$ & $\begin{array}{l}\text { galvanized } \\
\text { steel } \\
\text { sheet/zinc- } \\
\text { plated mild } \\
\text { steel sheet }\end{array}$ & $\begin{array}{c}300 \mathrm{~h} 250{ }^{\circ} \mathrm{C} \text { in } \\
\text { air }\end{array}$ & 0.88 & $\begin{array}{c}0.2 \\
\left(100^{\circ} \mathrm{C}\right)\end{array}$ & 77 \\
\hline $\mathrm{ZrO}_{2}$ & $\mathrm{Zr}$ & Sputtering & Glass & --- & 0.97 & $\begin{array}{l}0.05^{*} \\
\left(80^{\circ} \mathrm{C}\right)\end{array}$ & 78 \\
\hline SS-N & SS & Sputtering & Glass & --- & 0.91 & $\begin{array}{l}0.06^{*} \\
\left(82{ }^{\circ} \mathrm{C}\right)\end{array}$ & 79 \\
\hline HfMoN & $\mathrm{Hf} / \mathrm{Mo}$ & Sputtering & $\begin{array}{l}\text { Stainless } \\
\text { Steel }\end{array}$ & $\begin{array}{c}200 \mathrm{~h} @ 650{ }^{\circ} \mathrm{C} \\
\text { in vacuum } \\
34 \mathrm{~h} @ 475{ }^{\circ} \mathrm{C} \\
\text { in air }\end{array}$ & $0.94 \sim 0.95$ & $\begin{array}{l}0.13 \sim 0.14^{*} \\
\left(82^{\circ} \mathrm{C}\right)\end{array}$ & 80 \\
\hline
\end{tabular}

\section{1. $\mathrm{Cr}_{2} \mathrm{O}_{3}$-based cermets}


Black chrome, a complex graded $\mathrm{Cr}-\mathrm{Cr}_{2} \mathrm{O}_{3}$ composite on an $\mathrm{Al}$ or Ni substrate, can be produced by electroplating. McDonald has prepared electroplated black chrome on a $2 \mathrm{ft} \times 4 \mathrm{ft}$ collector tube sheet ${ }^{20}$. The absorptance based on the air mass 2 spectrum (AM 2) and emittance based on the $121{ }^{\circ} \mathrm{C}$ blackbody spectrum are 0.868 and 0.088 , respectively. The microstructure and thermal stability of black chrome have also been surveyed. Lampert and Washburn investigated the chemical and microstructural stability of black chrome at different temperatures and atmospheres ${ }^{19}$. There was little change on the microstructure and optical performance when annealed below $300{ }^{\circ} \mathrm{C}$ for a short term. A microcrystalline $\mathrm{Cr}_{2} \mathrm{O}_{3}$ phase was found after annealing at over $400{ }^{\circ} \mathrm{C}$, and when the temperature increased to $500{ }^{\circ} \mathrm{C}$, a new phase $\mathrm{Cr}_{3} \mathrm{O}_{4}$ appeared. An appreciable degradation of the optical performance was not observed up to $300{ }^{\circ} \mathrm{C}$; a mild degradation was found near $400{ }^{\circ} \mathrm{C}$. Major degradation appeared between $500{ }^{\circ} \mathrm{C}$ and $600{ }^{\circ} \mathrm{C}$. The thermal stability of the coatings after long-term annealing (134 hours) at $350{ }^{\circ} \mathrm{C}$ in air was tested by Ritchie et al. on electroplated black chrome ${ }^{45}$. To further optimize the thermal stability of electrodeposited black chrome, Pettit et al. carried out a series of experiments through changing the bath composition (chromic acid, acetic acid, trivalent chromium and iron), substrate, plating current density, time, and temperature $^{17}$. The most stable coatings were achieved with lower concentrations of trivalent chromium and additional agents. The solar absorptance should be stable at 0.96 for years of operation at $300{ }^{\circ} \mathrm{C}$ in air, when suitable techniques are applied.

Besides electroplating, physical vapor deposition has also been employed to prepare $\mathrm{Cr}_{2} \mathrm{O}_{3^{-}}$ based spectrally-selective cermets. Fan et al. deposited absorbers with a $\mathrm{Cr} / \mathrm{Cr}-\mathrm{Cr}_{2} \mathrm{O}_{3} / \mathrm{Cr}_{2} \mathrm{O}_{3}$ threelayer structure with a solar absorptance of 0.92 and a thermal emittance of 0.08 . A co-sputtering technique was applied in the deposition process of the $\mathrm{Cr}-\mathrm{Cr}_{2} \mathrm{O}_{3}$ cermet layer, which resulted in a similar optical performance compared to the electroplated black chrome ${ }^{40}$. Cermets can also be deposited using reactive sputtering with direct current (DC) power. Much work associated with $\mathrm{Cr}_{2} \mathrm{O}_{3}$ cermet-based spectrally-selective absorbers has been done. Teixeira et al. prepared graded layers of $\mathrm{Cr}-\mathrm{Cr}_{2} \mathrm{O}_{3}$ on $\mathrm{Cu}$ substrates by varying the oxygen gas flow and achieved absorbers with solar absorptances in the range of 0.90 to 0.94 and thermal emittances of $0.04^{39}$. Further optimization of the graded cermet film structure was carried out by Nunes et al. ${ }^{46}$. They proposed the configuration of four-layer coatings consisting of one anti-reflection layer on top of three cermet layers in which the $\mathrm{Cr}$ metal fraction decreases from substrate to surface. A solar aborptance of 0.94 and a thermal emittance of 0.06 at $82{ }^{\circ} \mathrm{C}$ were obtained. Yin et al. developed another film structure 
with an LHL configuration (L: low metal volume fraction in cermet, $\mathrm{H}$ : high metal volume fraction in cermet) made by changing the target current ${ }^{47}$. The absorber deposited on an optical slide coated with $200 \sim 400 \mathrm{~nm}$ of chromium had a solar absorptance in the range of $0.92 \sim 0.96$ and a thermal emittance between 0.05 and 0.08 at $100{ }^{\circ} \mathrm{C}$. The stability of coatings upon annealing at $170{ }^{\circ} \mathrm{C}$ for a long time (840 days) indicated it was suitable for solar hot water applications. As shown in Fig. 7, the reflection spectra after annealing at $200{ }^{\circ} \mathrm{C}, 300{ }^{\circ} \mathrm{C}, 400{ }^{\circ} \mathrm{C}$ and $500{ }^{\circ} \mathrm{C}$ in vacuum for 1 hour demonstrated the coatings were thermally stable up to 300 to $400{ }^{\circ} \mathrm{C}$. As for the preparation on a large scale, Graf et al. prepared sputtered solar absorber coatings $\left(\sim 60 \mathrm{~m}^{2}\right)$ on copper sheets based on chromium oxynitride by using DC-magnetron sputtering ${ }^{48}$. The absorbers showed good optical properties with $\alpha_{\mathrm{s}}>0.93$ and $\varepsilon_{\mathrm{t}}<0.07$ at $100{ }^{\circ} \mathrm{C}$.

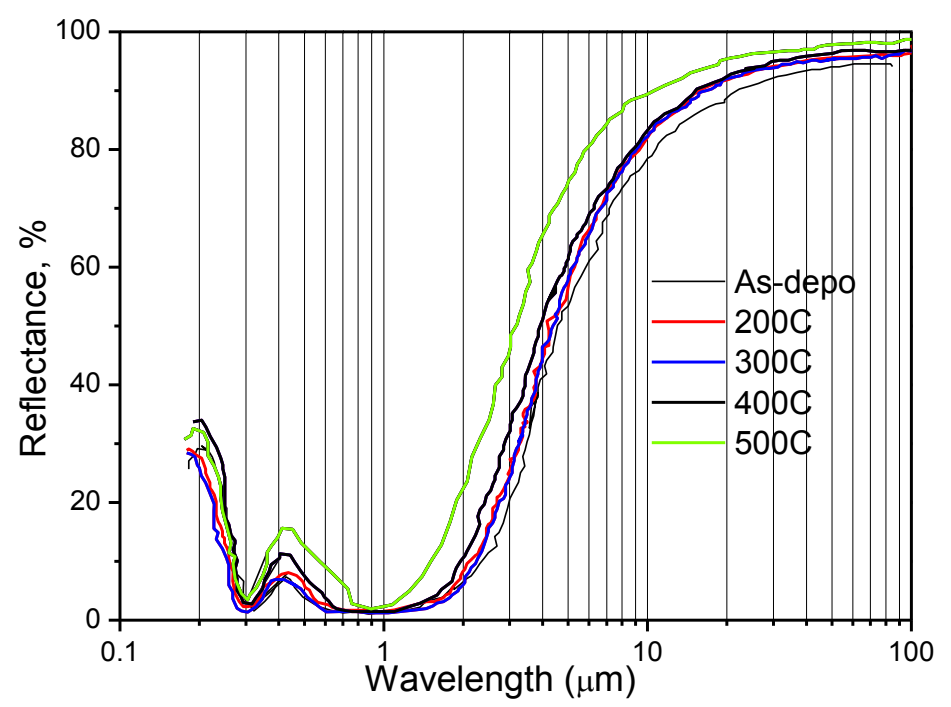

Fig. 7. Reflectance spectra of an LHL profile $\mathrm{Cr}_{-}-\mathrm{Cr}_{2} \mathrm{O}_{3}$ cermet spectrally-selective coating on an optical slide coated with $200 \sim 400 \mathrm{~nm}$ of chromium, after treatment under different annealing temperatures. Reprinted from ref. 47 with permission.

Figure 8 summarizes the spectral selectivity of black chrome produced through electroplating and physical vapor deposition. The highest solar absorptance of surfaces obtained from those different methods is almost the same, however high thermal emittance cannot be avoided on the coatings prepared by electroplating. Although the cost of electroplating is low, the environmental issues caused by electroplating should result in it being replaced by another manufacturing method in the future. 


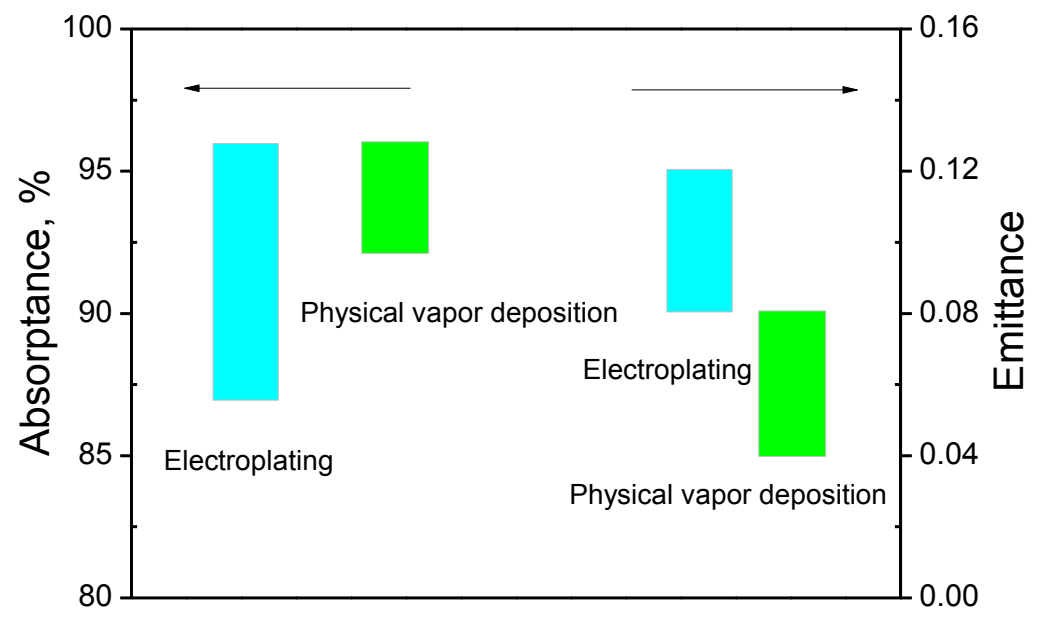

Fig. 8. The comparison of solar absorptance and thermal emittance of black chrome prepared by electroplating ${ }^{17,19,20}$ and physical vapor deposition ${ }^{39,40,46,47}$. The emittance was obtained at $82^{\circ} \mathrm{C}$ or $100{ }^{\circ} \mathrm{C}$.

\section{2. $\mathrm{Al}_{2} \mathrm{O}_{3}$-based cermets}

$\mathrm{Al}_{2} \mathrm{O}_{3}$-based cermet coatings which have excellent optical properties and thermal stabilities have been extensively investigated as spectrally-selective absorbers. Nickel-pigmented anodized aluminum (Ni particles embedded in anodized aluminum) was prepared by Kumar et al. by anodizing Al sheets or foil, followed by electrolysis in a Watt's type of nickel electroplating bath with a thick $\mathrm{Ni}$ sheet as a counter electrode ${ }^{49}$. They also studied the correlation of anodizing parameters with spectral selectivity. The solar absorptance and thermal emittance can be varied by adjusting the anodizing parameters, such as the bath temperature, anodization voltage, anodization time, and the concentration of $\mathrm{H}_{2} \mathrm{SO}_{4}$ and $\mathrm{H}_{3} \mathrm{PO}_{4}$. To improve the corrosion resistance of those solar absorbers, Moller et al. developed a hydrophobic post treatment method ${ }^{50}$, which seemed to be a promising alternative to replace the other sealing methods for spectrally-selective absorber surfaces. Other techniques, such as, co-evaporation, reactive sputtering, and solution based methods, were also employed to prepare $\mathrm{Ni}-\mathrm{Al}_{2} \mathrm{O}_{3}$ cermet-based solar selective surfaces. Craighead et al. investigated the spectral selectivity of a $\mathrm{Ni}-\mathrm{Al}_{2} \mathrm{O}_{3}$ cermet deposited by duel-electron-beam evaporation and a high solar absorptance of 0.94 at air mass 2 was achieved ${ }^{23}$. RF magnetron sputtering was used to prepare $\mathrm{Ni}-\mathrm{Al}_{2} \mathrm{O}_{3}$ cermet films by Sathiaraj et al ${ }^{21,22}$. The metal fractions of the cermet layers were varied by using targets with different compositions and by co-sputtering the 
target with additional nickel pellets arranged along the magnetron ring. The reflection spectra of the $\mathrm{Ni}-\mathrm{Al}_{2} \mathrm{O}_{3}$ cermet layer $\left(65 \mathrm{~nm}\right.$ thick) with and without a $\mathrm{SiO}_{2}$ anti-reflection layer are shown in Fig. 9. The solar absorptance of 0.94 and thermal emittance of 0.07 at $100{ }^{\circ} \mathrm{C}$ were calculated from the reflectance curve in Fig. 9. The $\mathrm{Ni}-\mathrm{Al}_{2} \mathrm{O}_{3}$ coating deposited on the molybdenum-coated nickelplated stainless steel with a protective $\mathrm{SiO}_{2}$ coating as an anti-reflection layer was stable up to 500 ${ }^{\circ} \mathrm{C}$ in air.

Solution-chemical methods were also developed to prepare the selective solar absorbers. Boström et al. employed a promising novel solution-based method to synthesize $\mathrm{Ni}_{-}-\mathrm{Al}_{2} \mathrm{O}_{3}$ cermetbased coatings on aluminum substrates ${ }^{51}$. The optimal coating, with a nickel content of $65 \%$, a thickness of $0.1 \mu \mathrm{m}$, and particle size of $\sim 10 \mathrm{~nm}$ has a normal solar absorptance of 0.83 and a normal thermal emittance of 0.03 at $100{ }^{\circ} \mathrm{C}$. To further optimize the spectral selectivity, an antireflection layer was added with a sol-gel process. The silica, hybrid silica or alumina AR film was obtained after annealing the coatings at $580{ }^{\circ} \mathrm{C}^{52}$. The optimized sample was achieved when alumina was used as an AR coating; the absorber had a solar absorptance of 0.93 and a thermal emittance of 0.03 at $100{ }^{\circ} \mathrm{C}$. The structure and morphology of nickel-alumina/silica spectrallyselective absorbers were investigated by Boström et al. ${ }^{53}$. The size of the Ni metal particles dispersed in the $\mathrm{Al}_{2} \mathrm{O}_{3}$ was in the range of 3-10 nm, which is small enough compared with the wavelengths of interest. Micro-cracking can be avoided by using hybrid silica compared with pure silica. $\mathrm{Ni}-\mathrm{Al}_{2} \mathrm{O}_{3}$ coatings prepared via an aqueous solution-chemical method was suggested by $\mathrm{Li}$ et $a l .{ }^{43}$. In the process of preparation, the aqueous solution had many advantages, such as its abundance, lower cost, and low toxicity. They found that a single $\mathrm{Ni}^{-} \mathrm{Al}_{2} \mathrm{O}_{3}$ coating on an aluminum substrate demonstrated a high normal solar absorptance of 0.85 and a low thermal emittance of 0.03 at $100{ }^{\circ} \mathrm{C}$, and a three-layer coating consisting of a double absorption layer and one anti-reflection layer indicated a better selectivity with a solar absorptance of 0.93 and a thermal emittance of 0.05 at $100{ }^{\circ} \mathrm{C}$. The thermal stability of the three-layer coating was evaluated in air at $250{ }^{\circ} \mathrm{C}$ and $300{ }^{\circ} \mathrm{C}$, as shown in Fig. 10, which indicated it was stable in air up to $300{ }^{\circ} \mathrm{C}$. Wang et al. observed that surface plasmon polaritons enhanced solar absorption in a Ni nanochain- $\mathrm{Al}_{2} \mathrm{O}_{3}$ cermet structure, which demonstrated a high solar absorptance exceeding 0.90 and low thermal emittance of less than $0.10^{44}$. The authors also discovered that the spectral selectivity can be tailored by changing the length of Ni nanochains. 


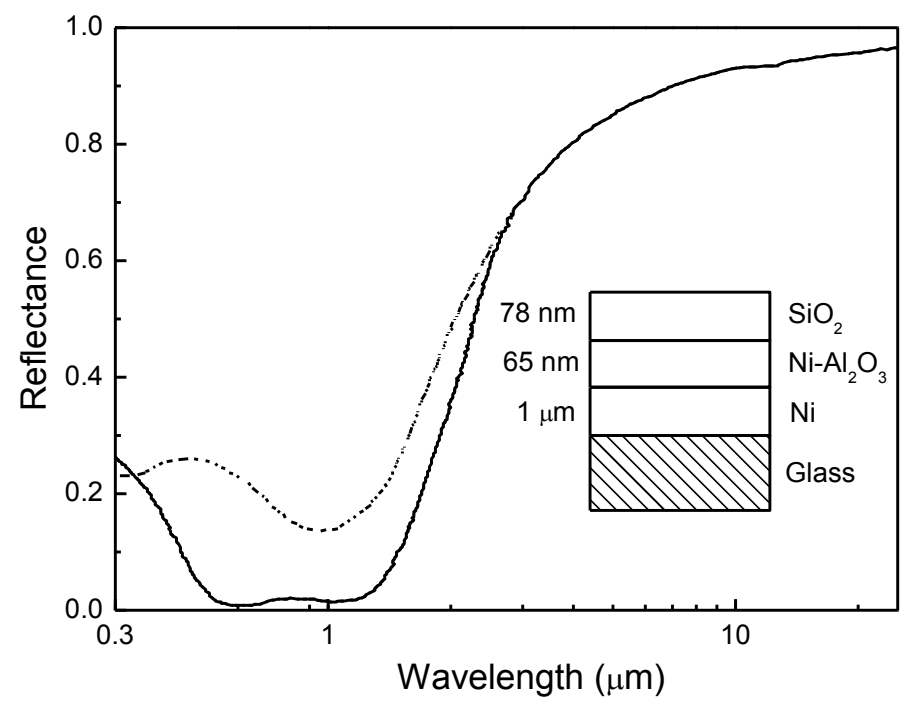

Fig. 9. The reflectance spectra of a $65 \mathrm{~nm} \mathrm{Ni}-\mathrm{Al}_{2} \mathrm{O}_{3}$ film (dashed line) and after overcoating with 78 nm of $\mathrm{SiO}_{2}$ (solid line). Reprinted from ref. 22 with permission.

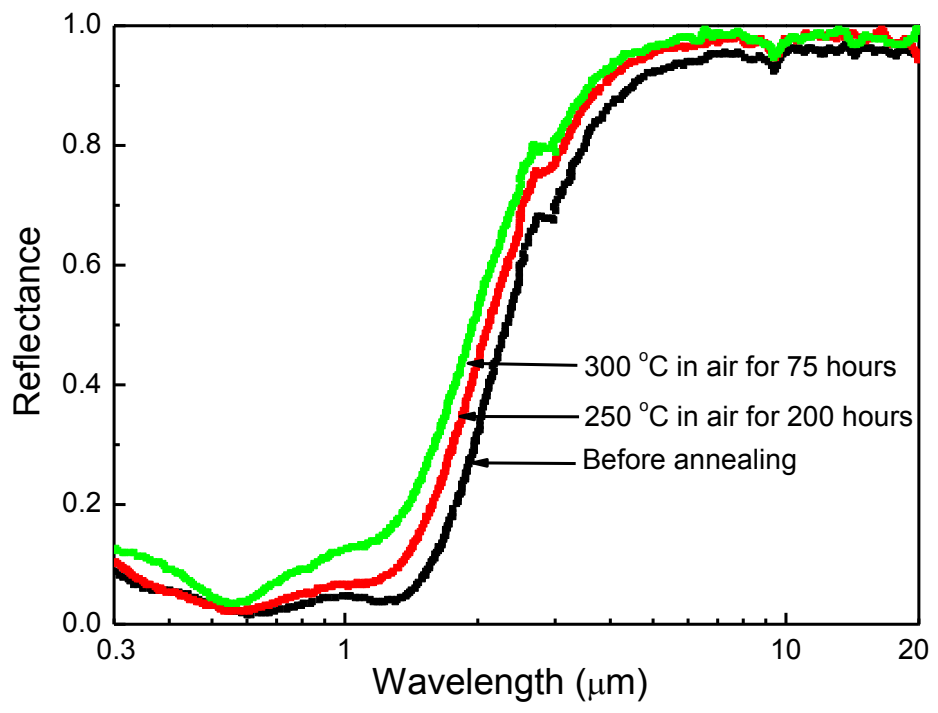

Fig. 10. Thermal stability of three-layer sample $\mathrm{Ni}_{90} \mathrm{Al}_{10} / \mathrm{Ni}_{40} / \mathrm{Al}_{60} / \mathrm{SiO}_{2}$ in air after annealing at 250 ${ }^{\circ} \mathrm{C}$ and $300{ }^{\circ} \mathrm{C}$, respectively. Reprinted from ref. 43 with permission.

Besides $\mathrm{Ni}$, other metals such as $\mathrm{Ag}, \mathrm{Co}, \mathrm{Ti}, \mathrm{Mo}, \mathrm{W}$, and Pt were also used as inclusions in an $\mathrm{Al}_{2} \mathrm{O}_{3}$ matrix. Niklasson et al. prepared $\mathrm{Co}-\mathrm{Al}_{2} \mathrm{O}_{3}$ cermet films by vacuum co-evaporation of $\mathrm{Co}$ 
and $\mathrm{Al}_{2} \mathrm{O}_{3}{ }^{35}$. The optimized absorber, with a $70 \mathrm{~nm} \mathrm{Co-} \mathrm{Al}_{2} \mathrm{O}_{3}(58 \mathrm{vol} \% \mathrm{Co})$ cermet layer and a 70 $\mathrm{nm} \mathrm{Al}_{2} \mathrm{O}_{3}$ anti-reflection layer on Corning 7059 glass coated with an opaque Ni layer, had a solar absorptance of 0.95 and a thermal emittance of near 0.10 at $100{ }^{\circ} \mathrm{C}$. Titanium - a lightweight metal with good corrosion resistance - was embedded in $\mathrm{Al}_{2} \mathrm{O}_{3}$ dielectric materials through pulsed laser deposition by Chen et al. ${ }^{54}$. The extinction coefficient increased and the real part of the refractive index decreased with increasing Ti content in the UV and visible wavelength range. The two-layer $\mathrm{Ti}-\mathrm{Al}_{2} \mathrm{O}_{3}$ film demonstrated promising spectral selectivity. $\mathrm{Ag}-\mathrm{Al}_{2} \mathrm{O}_{3}$ cermet films on copper, silicon and glass were also prepared with an unbalanced magnetron sputtering technique. A broad absorption peak was observed at $\sim 610 \mathrm{~nm}$, which was due to the surface plasmon resonance of $\mathrm{Ag}$ nanoparticles embedded in the $\mathrm{Al}_{2} \mathrm{O}_{3}$ matrix ${ }^{55}$. This structure exhibited a high solar absorptance (0.93) and low thermal emittance $(0.04 \sim 0.05)$ at $82{ }^{\circ} \mathrm{C}$. There was no shift of Raman peaks in the coatings upon annealing for 2 hours in vacuum at $400{ }^{\circ} \mathrm{C}$. Mo was also investigated as a metal addition in $\mathrm{Al}_{2} \mathrm{O}_{3}$ cermets. Graded $\mathrm{Mo}-\mathrm{Al}_{2} \mathrm{O}_{3}$ cermet coatings on $\mathrm{Al}$ or $\mathrm{Cu}$ substrates were produced by gradually adjusting the oxygen gas flow during reactive sputtering by Teixeira et al. ${ }^{39}$. Those coatings demonstrated a good spectral selectivity with a solar absorptance of $0.88-0.94$ and a thermal emittance of $0.09-0.15$. The microstructure and spectral selectivity of a series of films including $\mathrm{Mo}, \mathrm{Al}_{2} \mathrm{O}_{3}, \mathrm{Mo} / \mathrm{Al}_{2} \mathrm{O}_{3}$ tandems, and $\mathrm{Mo}-\mathrm{Al}_{2} \mathrm{O}_{3}$ multilayers deposited on stainless steel via magnetron sputtering were investigated ${ }^{56}$. The optimized absorber, with double $\mathrm{Mo} / \mathrm{Al}_{2} \mathrm{O}_{3}$ cermet layers and one $\mathrm{Al}_{2} \mathrm{O}_{3}$ anti-reflection layer, had a solar absorptance of 0.92 and thermal emittance of 0.19 at $80{ }^{\circ} \mathrm{C}$. After annealing at $800{ }^{\circ} \mathrm{C}$ for 2 hours in vacuum, the solar absorptance decreased to 0.91 and the thermal emittance increased to 0.27 . There were some defects, such as widened boundaries and cracks and holes in the $\mathrm{Al}_{2} \mathrm{O}_{3}$ layer after high temperature treatment $\left(>650{ }^{\circ} \mathrm{C}\right)$, which could induce the Mo diffusion and deteriorate the spectral selectivity of the coatings. The improved thermal stability of $\mathrm{Mo}-\mathrm{Al}_{2} \mathrm{O}_{3}$ cermet-based spectrally-selective absorbers was achieved by Cheng et al. using a similar preparation procedure as Du's work ${ }^{57}$. The stability of W embedded in an $\mathrm{Al}_{2} \mathrm{O}_{3}$ matrix prepared by co-sputtering was investigated by Antonaia et al. ${ }^{58}$. There was a slight change in the reflectance spectrum upon annealing at $580{ }^{\circ} \mathrm{C}$ for 2 days in vacuum, but thermo-mechanical degradation, such as fracturing, peeling, and adhesion, did not appear. The stability of each layer, investigated with FTIR and XRD data, indicated that the tungsten metal back reflector underwent a phase transition from $\beta$ to $\alpha$; tungsten in $\mathrm{Al}_{2} \mathrm{O}_{3}$ was partially oxidized; and the amorphous $\mathrm{Al}_{2} \mathrm{O}_{3}$ tended to form the $\gamma$ phase upon annealing. For higher temperature applications 
(up to $650{ }^{\circ} \mathrm{C}$ ), noble metals were chosen as the inclusions in the dielectric matrix due to their chemical inertness and stability. Graded $\mathrm{Pt}-\mathrm{Al}_{2} \mathrm{O}_{3}$ composites were also prepared through the coevaporation of $\mathrm{Pt}$ and $\mathrm{Al}_{2} \mathrm{O}_{3}$ and a textured $\mathrm{SiO}_{2}$ layer was obtained by etching with a plasma of $\mathrm{CF}_{4}$ gas. With the help of the textured $\mathrm{SiO}_{2}$ anti-reflection layer, the solar absorptivity of this graded coating was as high as $0.98^{36}$. Nuru et al. prepared $\mathrm{Pt}-\mathrm{Al}_{2} \mathrm{O}_{3}$ on a Mo-coated stainless steel substrate using radio-frequency sputtering ${ }^{59}$. The XRD indicated that the $\mathrm{Al}_{2} \mathrm{O}_{3}$ matrix was fully amorphous, and the size of the Pt inclusions was about 3.2-4.7 $\mathrm{nm}$ using the Debye-Scherer approximation, which is consistent with the results obtained from SEM and AFM. An absorptance exceeding 0.98 can be achieved across the UV/visible/near IR range.

The solar absorptance and thermal emittance of the typical $\mathrm{Al}_{2} \mathrm{O}_{3}$-based cermet absorbers with different metal inclusions ( $\mathrm{Ag}, \mathrm{Co}, \mathrm{Mo}, \mathrm{Ni}, \mathrm{Pt}$, and $\mathrm{W}$ ) are summarized in Fig. 11. Although the IR reflector layer or substrate has a large effect on the thermal emittance, the metal inclusions, especially in the bottom layer adjacent to the substrate or IR reflector layer, also affect the thermal emittance due to the similar metal characteristics in this layer. Among those metal inclusions, the surface based on $\mathrm{Ag}$ embedded in $\mathrm{Al}_{2} \mathrm{O}_{3}$ demonstrates a low thermal emittance at $82{ }^{\circ} \mathrm{C}$. The solar absorbers which had a $\mathrm{W}-\mathrm{Al}_{2} \mathrm{O}_{3}$ absorption layer showed a thermal emittance of 0.1 at $400{ }^{\circ} \mathrm{C}$, which is promising for CSP applications. $\mathrm{Ni}_{-} \mathrm{Al}_{2} \mathrm{O}_{3}$ cermet-based absorbers, marked by the ellipse in Fig. 11, display different emittances ascribed to different preparation techniques. A high thermal emittance of $0.1-0.2$ was found in the absorber prepared by electrochemical deposition. Physical deposition and solution-chemical methods can result in low thermal emittances. The absorptances of those surfaces were in the range of $0.88 \sim 0.98$. The highest was obtained with a $\mathrm{Pt}-\mathrm{Al}_{2} \mathrm{O}_{3}$ absorber. 


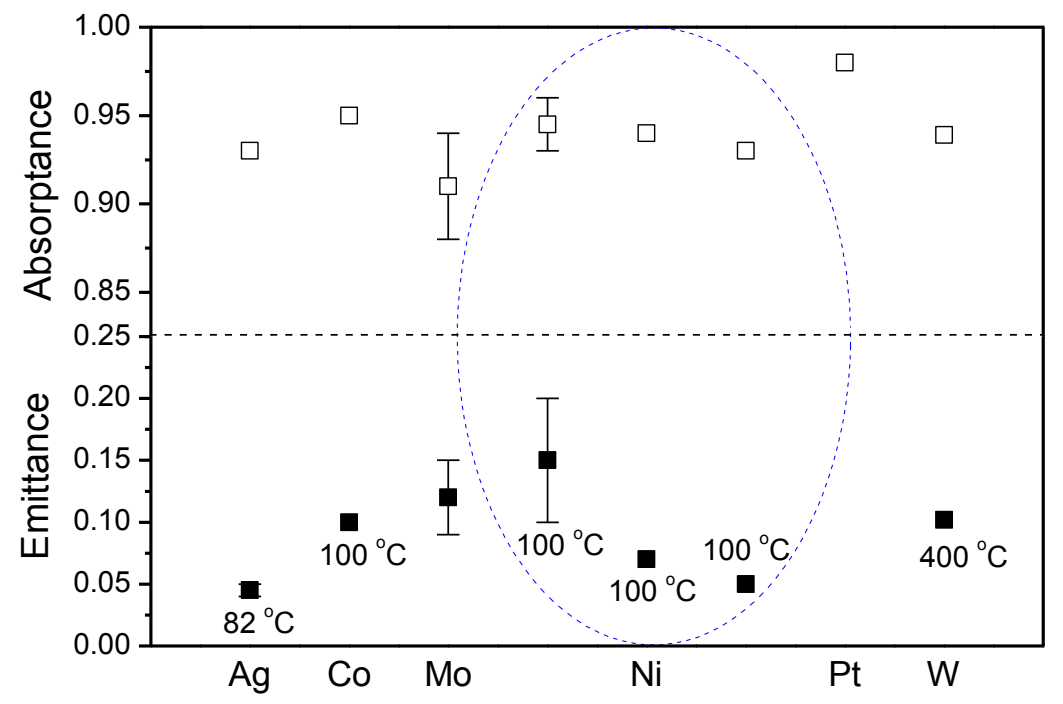

Fig. 11. The solar absorptance and thermal emittance of spectrally-selective absorbers with different metals (Ag, Co, Mo, Ni, Pt and W) embedded in an $\mathrm{Al}_{2} \mathrm{O}_{3}$ matrix ${ }^{22,33,35,36,39,43,55,58}$.

\subsection{AIN-based cermets}

Aluminum nitride, which has high thermal and chemical stability, was chosen as a dielectric for some cermets. Zhang et al. carried out extensive work on AlN-based cermets for absorber coatings ${ }^{41,42,60-66}$. W-AlN cermets were prepared by simultaneous deposition of $\mathrm{Al}$ and $\mathrm{W}$ in a gas mixture of argon and nitrogen. Due to the high chemical reactivity of aluminum with nitrogen and the excellent nitriding resistance of tungsten metal, AlN dielectrics with tungsten inclusions can be achieved using DC reactive sputtering. As shown in Fig. 12, the reflectance spectra of the absorbers with double cermet layers and one AlN anti-reflection layer on an Al IR reflector coated substrate indicated a solar absorption of 0.939 and a normal thermal emittance of 0.039 at room temperature ${ }^{60}$. The film, after baking at $500{ }^{\circ} \mathrm{C}$ in vacuum, demonstrated a nearly identical emittance as that of a pristine film. Calculations based on a modified Bruggeman method ${ }^{67}$ to optimize the films were carried out by Zhang ${ }^{41}$. Three-layer and four-layer cermet coatings based on the calculations demonstrated similar spectrally-selective characteristics. The optimized coatings with film structures of AlN/W-AlN (low metal volume fraction (LMVF) /W-AlN (high metal volume fraction (HMVF) /Al have a high solar absorptance of 0.953 and a near-normal emittance of 0.051 at $80{ }^{\circ} \mathrm{C}$ under $2 \mathrm{X}$ optical concentration. Similar to a pure AIN dielectric, the LMVF cermet was transparent in the IR and therefore had a similar thermal emittance. The HMVF cermet with the metal filling factor of 0.56-0.58 had metal-like characteristics and had a large effect on the emittance of the 
structure. In these HMVF cermets, the contribution of the IR reflector layer (W, $\mathrm{Cu}$ or $\mathrm{Al}$ ) on the emittance can be ignored. Since stainless steel (SS) has excellent nitriding resistance, it can be used as metal component in AlN-based cermets. When depositing AlN via reactive sputtering of Al with nitrogen, there is a sharp transition from the metal mode to the dielectric mode depending on the nitrogen partial pressure ${ }^{61}$. It is reasonable to adjust the composition of SS-AlN cermet by changing the deposition time ratio of SS to AIN. The design of double cermet structures was also employed in this system. The reflectance spectrum can be shifted by changing the thickness of each layer. Reducing the thickness of the HMVF cermet layer from $64 \mathrm{~nm}$ to $53 \mathrm{~nm}$ induced a shift towards shorter wavelengths. Increasing the thickness of the LMVF cermet layer from $16 \mathrm{~nm}$ to $32 \mathrm{~nm}$ resulted in a shift towards longer wavelengths. The thermal stability of the sample with the configuration of AlN (70 nm)/SS-AlN(LMVF) (16 nm)/SS-AlN(HMVF) (53 nm) was inspected and is shown in Fig. 13. There was a slight change in the reflectance spectrum after baking at $500{ }^{\circ} \mathrm{C}$ for 1 hour in vacuum, which resulted in an increase in solar absorptance from 0.933 to 0.937 and an increase in thermal emittance from 0.025 to 0.029 at $20{ }^{\circ} \mathrm{C}$. A commercial-scale cylindrical DC magnetron sputter coater was developed by Zhang et al. in $1998^{66}$, which can be used to deposit metal-aluminum nitride cermet coatings on glass tubes. The chamber can accommodate thirty-two glass tubes with outside diameters of $37 \mathrm{~mm}$ and lengths of $1.2 \mathrm{~m}$. Zhao et al. prepared Al-AlN cermets through the reactive sputtering of $\mathrm{Al}$ with nitrogen gas ${ }^{68}$. The different composites of AlAlN cermets can be tuned by changing the nitrogen gas flow during the process of sputtering. The optical parameters of the cermets were determined using a dielectric function model of the two constituents in Bruggeman's equation. The high solar absorptance of 0.97 can be predicted by modeling the film structure as two graded absorption layers and an anti-reflection layer. The optimized solar absorber demonstrated a high solar absorptance of 0.96 . The design of a textured surface was applied in the Al-N system. Different surface roughnesses of sputtered Al films were achieved through a method of two-step deposition of the Al film with different substrate temperatures $^{69}$. With increasing the substrate temperature of the lower reflector layer, the surface roughness increases. Compared with the flat film, a surface with suitable roughness can improve the solar absorptance without increasing the thermal emittance. 


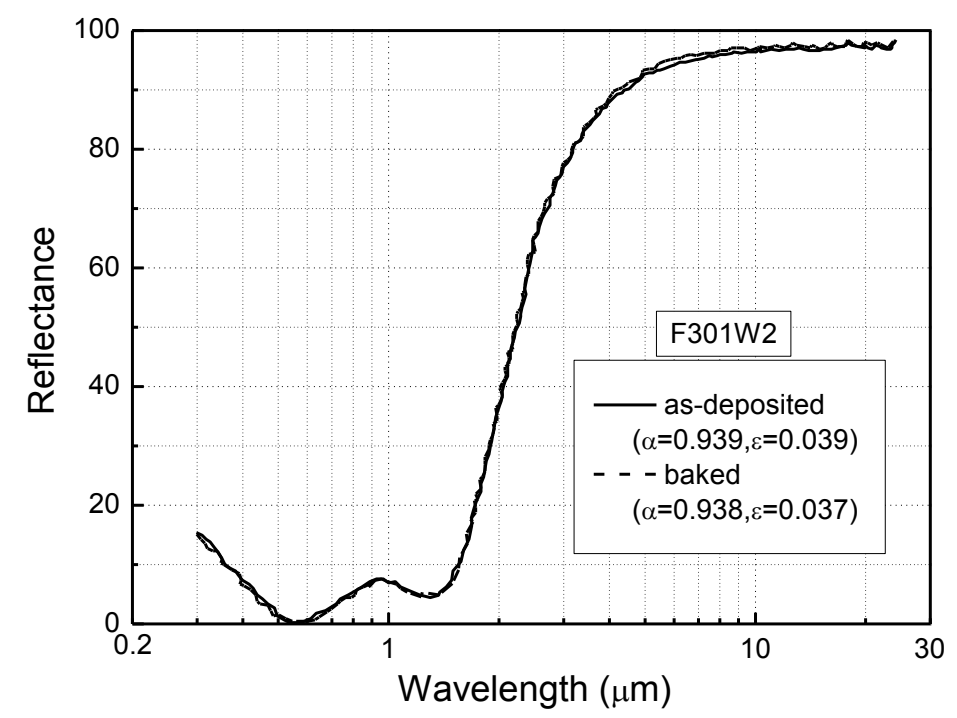

Fig. 12. The near normal reflectance spectra of sample F301W2 with the structure of AlN/WAlN(LMVF)/W-AlN(HMVF)/Al. The solid line is as-deposited; the dashed line is after baking in vacuum at $500{ }^{\circ} \mathrm{C}$ for 1 hour. Reprinted from ref. 61 with permission.

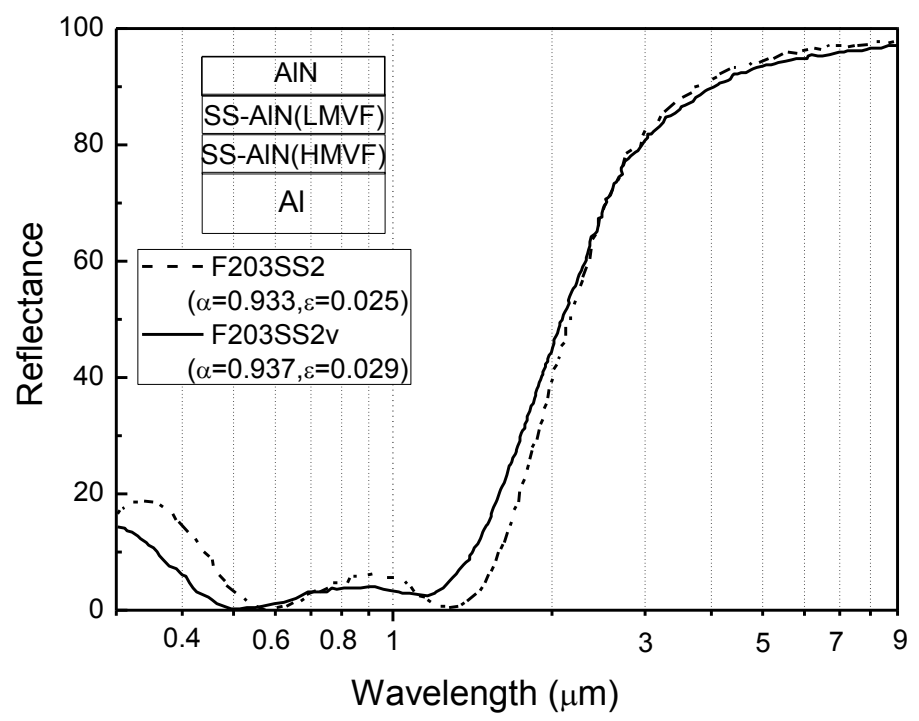

Fig. 13. The reflectance spectrum of F203SS2 baked in vacuum at $500{ }^{\circ} \mathrm{C}$ for 1 hour (solid curve). As a comparison, the reflectance spectrum of the as-deposited film is also included (dashed curve). Reprinted from ref. 61 with permission.

\section{4. $\mathrm{SiO}_{2}$-based cermets}


Amorphous silicon dioxide was long used as anti-reflection layer. It can be utilized in cermets as the dielectric material due to its high chemical and thermal stability. The metals $\mathrm{Cu}, \mathrm{Ag}$, $\mathrm{Au}, \mathrm{Ni}$ and $\mathrm{Mo}$ embedded in $\mathrm{SiO}_{2}$ media have been investigated as spectrally-selective coatings ${ }^{70-74}$. $\mathrm{Cu}-\mathrm{SiO}_{2}$ cermets prepared by simultaneous evaporation of silicon dioxide and copper with an electron beam heater and electric-resistance heater, respectively, were used as absorption layer for spectrally-selective absorbers by Garnich et $a l^{72}$. The filling factor of metal in the dielectric matrix and the thickness of the cermets can directly determine the spectral selectivity of the coatings. The transition wavelength can be adjusted by changing the filling factor and thickness of the cermet layer. With the optimum thickness $(50-200 \mathrm{~nm})$ and filling factor $(20 \%-40 \%)$ of the cermet, the transition wavelength can shift to shorter wavelengths with decreasing thickness and filling factor of the cermet layer. $\mathrm{Cu}-\mathrm{SiO}_{2} / \mathrm{Cu}$ tandems showed large degradation upon tempering above $400{ }^{\circ} \mathrm{C}$ in vacuum due to $\mathrm{Cu}$ diffusion. Structures comprising double absorption layers of HMVF and LMVF were employed in the $\mathrm{Cu}-\mathrm{SiO}_{2}$ system. Zhang et al. deposited double absorption layers of $\mathrm{Cu}-\mathrm{SiO}_{2}$ cermets by co-evaporation of $\mathrm{Cu}$ and $\mathrm{SiO}_{2}{ }^{34}$. With the help of a $\mathrm{SiO}_{2}$ anti-reflection layer, the absorber demonstrated a high solar absorptance of 0.911 and low normal thermal emittance of 0.0196 at $50{ }^{\circ} \mathrm{C}$. To improve the thermal stability of $\mathrm{SiO}_{2}$-based cermets, Okuyama et al. chose $\mathrm{Ni}$ as the inclusion ${ }^{73}$. The $\mathrm{Ni}-\mathrm{SiO}_{2}$ cermets were prepared by evaporation of a pressed mixture of $\mathrm{Ni}$ and $\mathrm{SiO}_{2}$. The complex refractive index was calculated by fitting a model to the transmittance and reflectance data. The real part of the refractive index of the $\mathrm{Ni}_{-} \mathrm{SiO}_{2}$ cermet was slightly larger than that of $\mathrm{SiO}_{2}$. The coatings with $87 \mathrm{~nm}$ of $\mathrm{Ni}-\mathrm{SiO}_{2}$ cermet and $73 \mathrm{~nm}$ of $\mathrm{SiO}_{2}$ demonstrated good optical properties with high absorptance in the visible and near-IR range and high reflectance in the IR range. A solar absorptance of 0.90 can be obtained with this absorber. The thermal emittance, which was measured by cooling the heated sample, increased with temperature. The thermal stability of the coatings was good; little spectral and mechanical degradation was found after treatment in a vacuum at $420{ }^{\circ} \mathrm{C}$ for 40 hours and at $515^{\circ} \mathrm{C}$ for 12 hours. Farooq et al. utilized a cosputtering technique to prepare $\mathrm{Ni}-\mathrm{SiO}_{2}$ cermets and studied the influence of substrate choice, film thickness, and film composition on spectral selectivity ${ }^{75}$. The solar absorptance of coatings deposited on bulk aluminum was 0.91. A larger absorptance (0.96) and also a larger thermal emittance were found when the coatings were deposited on Ni-coated Al. This increase is probably due to the rough surface of the Ni-coated Al. As shown in Fig. 14, the reflectance spectrum of the surface with thick $\mathrm{Ni}-\mathrm{SiO}_{2}$ composites is shifted to longer wavelengths compared to that with thin 
$\mathrm{Ni}-\mathrm{SiO}_{2}$ composites. Gold was also embedded in a $\mathrm{SiO}_{2}$ matrix via co-evaporation of $\mathrm{Au}$ and $\mathrm{SiO}_{2}$ by electron beam evaporation ${ }^{74}$. The very low thermal emittance of $0.014 \pm 0.005$ at $100{ }^{\circ} \mathrm{C}$ was obtained from a thermal radiation experiment compared with the radiation of a black body. The

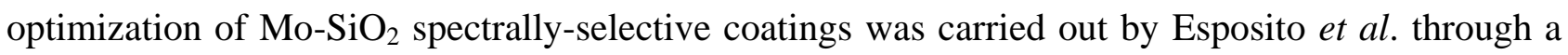
semi-empirical procedure ${ }^{71}$. The complex index of refraction of each layer was estimated from ellipsometric measurements and was used to simulate the photo-thermal parameters. The optimized coatings on stainless steel demonstrated a very low thermal emittance of less than 0.13 and a solar absorptance of 0.94 was measured in vacuum at $580{ }^{\circ} \mathrm{C}$. Further evaluation of the thermal stability of a $\mathrm{Mo}-\mathrm{SiO}_{2}$ selective surface was carried out at $754{ }^{\circ} \mathrm{C}^{70}$. There was little change of the XRD patterns of $\mathrm{LMVF} \mathrm{Mo}-\mathrm{SiO}_{2} / \mathrm{SiO}_{2}$ and $\mathrm{HMVF} \mathrm{Mo}-\mathrm{SiO}_{2} / \mathrm{SiO}_{2}$ after annealing at $754{ }^{\circ} \mathrm{C}$ for 2 hours in vacuum compared with the pristine ones, which indicated the $\mathrm{Mo}-\mathrm{SiO}_{2} / \mathrm{SiO}_{2}$ tandem was still amorphous even after annealing. The cermet coating on quartz glass with a Mo IR reflector $150 \mathrm{~nm}$ thick showed a high absorptance of 0.95 and a low emittance of 0.075 at $80{ }^{\circ} \mathrm{C}$ upon annealing at $754{ }^{\circ} \mathrm{C}$, and demonstrated a high thermal stability.

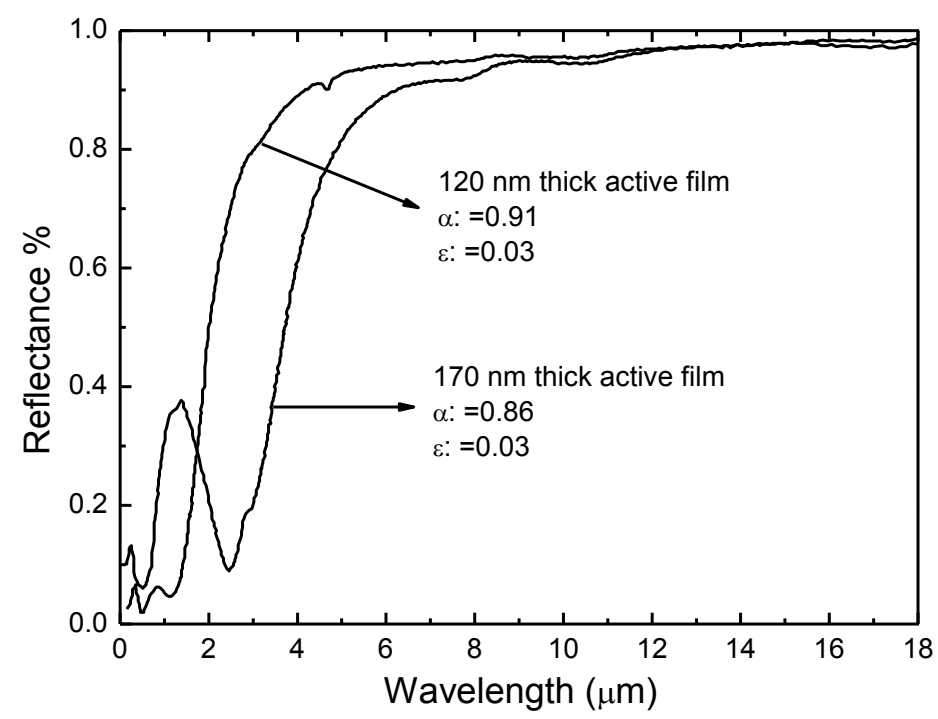

Fig. 14. The reflectance spectra of $\mathrm{Ni}-\mathrm{SiO}_{2}$ selective solar absorber coatings with different active film thicknesses. Reprinted from ref. 75 with permission.

The dependence of the spectral selectivity on the metal inclusions is depicted in Fig. 15. For the $\mathrm{Cu}, \mathrm{Au}, \mathrm{Mo}$, and $\mathrm{Ni} / \mathrm{SiO}_{2}$ absorbers, the IR reflector material is the same metal as the inclusion. An emittance of less than 0.03 was achieved on the absorbers using $\mathrm{Cu}$ or $\mathrm{Au}$ as a reflector layer, which is reasonable due to the low emissivity of $\mathrm{Cu}$ and $\mathrm{Au}$. Regarding the $\mathrm{Ni}^{-} \mathrm{SiO}_{2}$ cermet 
absorbers, the emittance of 0.03 was obtained with a bulk aluminum substrate; the high emittance of 0.14 was achieved with a $\mathrm{Ni}$-coated $\mathrm{Al}$ substrate. The $\mathrm{Mo}^{-} \mathrm{SiO}_{2}$ based absorber exhibited a low emittance even at $400{ }^{\circ} \mathrm{C}$, indicating its potential for many mid-temperature applications. The Au$\mathrm{SiO}_{2}$ based cermet has the lowest solar absorptance and the lowest thermal emittance, indicating the highly reflectivity of Au plays a role across the entire spectrum.

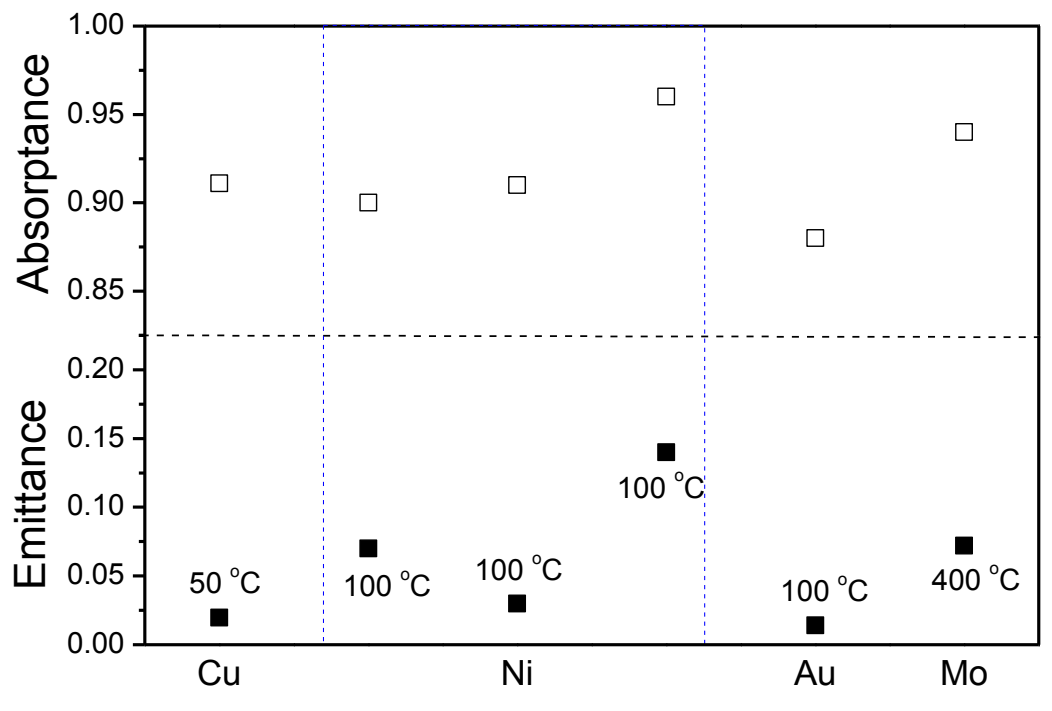

Fig. 15. The solar absorptance and thermal emittance of various spectrally-selective absorbers with different metals $(\mathrm{Cu}, \mathrm{Ni}, \mathrm{Au}$, and $\mathrm{Mo})$ embedded in an $\mathrm{SiO}_{2}$ host ${ }^{34,71,73-75}$.

\subsection{Other cermets}

Other composites such as black nickel and black molybdenum were developed for flat plate solar collectors. Gogna et al. utilized a chemical conversion technique to deposit black nickel coatings. Silmilar to black chrome, black nickel comprises nickel, zinc, nickel sulfide, and zinc sulfide $^{76}$. The solar absorptance and thermal emittance of black nickel deposited on galvanized iron depended strongly on the dipping time at different bath temperatures and solution $\mathrm{pH}$ values. With increasing dipping time, the solar absorptance increased and reached a saturated value before decreasing again slightly. However, the thermal emittance increased gradually due to the increased thickness of black nickel. There was no effect on the coatings deposited on galvanized iron or zinc electroplated aluminum substrates after a 6-month outdoor exposure test. A similar simple, low-cost 
technique was employed to prepare black molybdenum ${ }^{77}$. The optimized spectrally-selective absorbers had a solar absorptance of 0.88 and a thermal emittance of 0.2 . Good thermal stability and high adhesion were found on the coatings deposited on galvanized steel sheet and zinc-plated mild steel sheet.

The $\mathrm{Zr}-\mathrm{ZrO}_{2}$ cermets deposited via DC reactive sputtering were used as spectrally-selective coatings for solar absorbers ${ }^{78}$. The optimization of the film configuration was carried out with a numerical model to maximize the absorber efficiency. The optimized film with the structure of $\mathrm{Al}_{2} \mathrm{O}_{3} / \mathrm{Zr}-\mathrm{ZrO}_{2}(\mathrm{LMVF}) / \mathrm{Zr}-\mathrm{ZrO}_{2}$ (HMVF)/Al demonstrated a high solar absorptance of 0.96, a normal thermal emittance of 0.05 at $80{ }^{\circ} \mathrm{C}$, and good thermal stability at 300 to $350{ }^{\circ} \mathrm{C}$ in air. Using one stainless steel (SS) target, Juang et al. deposited SS/SS-N films by varying nitrogen gas flow ratios during deposition ${ }^{79}$. The HMVF SS/SS-N cermets could be obtained at a low nitrogen gas ratio. By increasing the nitrogen gas ratio to $15 \%$, the cermet was gradually changed to LMVF. It evolved into a dielectric material when the nitrogen gas ratio exceeded $17.5 \%$. The three-layer coatings comprising HMVF and LMVF cermet layers and a dielectric layer had a solar absorptance of 0.91 and a thermal emittance of 0.06 at $82{ }^{\circ} \mathrm{C}$, which was close to the predicted value. To extend the application to higher temperatures, HfN- and MoN-based materials were explored as spectrallyselective coatings due to their high thermal stability and excellent optical characteristics.

A new $\mathrm{HfMoN}(\mathrm{HMVF}) / \mathrm{HfMoN}(\mathrm{LMVF}) / \mathrm{HfON} / \mathrm{Al}_{2} \mathrm{O}_{3}$ tandem coating on a SS substrate was developed by Selvakumar et al. using reactive pulsed DC unbalanced magnetron sputtering ${ }^{80}$. Each layer was deposited using $\mathrm{Hf}$, Mo and Al metallic targets under different gas ratios of Ar, $\mathrm{N}_{2}$ and $\mathrm{O}_{2}$. The four-layer tandem exhibited high thermal stability in vacuum at $600{ }^{\circ} \mathrm{C}$ for 450 hours, $650{ }^{\circ} \mathrm{C}$ for 100 hours and in air at $475^{\circ} \mathrm{C}$ for 34 hours.

\section{Outlook and Conclusion}

For high-temperature CSP applications, achieving thermally-stable spectrally-selective absorbers remains a major challenge. One strategy is to explore new materials, including metal inclusions and dielectrics, which have high thermal stability and excellent optical properties for high temperature applications, especially above $500{ }^{\circ} \mathrm{C}$. Stable oxide and nitride materials, such as $\mathrm{Y}_{2} \mathrm{O}_{3}, \mathrm{ZrO}_{2}, \mathrm{HfN}$ and TiN, should be extensively investigated. Also, metal inclusions with high melting points and high nitriding and oxidation resistance, such as noble metals, should be an 
interesting topic for cermet-based spectrally-selective absorbers. Besides choosing stable materials for coatings, avoiding the diffusion of metal at high temperatures is another issue. Pretreatment of stainless steel substrates in air to form oxide coatings can prevent the diffusion between the metallic IR reflector and the substrate ${ }^{57}$. To maximize the absorber efficiency, multiple absorption mechanisms should be employed. As for cermet-based absorbers, we should fully take into account the interference effect with different layers as well as the intrinsic absorption of each cermet layer in the design of multilayer films. Accurate information on the cermet optical constants over a wide wavelength range is needed for simulations of multilayer designs. Regarding the cermet layer, the solar absorption strongly depends on the uniform distribution and suitable size of the metal inclusions in the dielectric, the particle size orientation, the metal volume fraction, as well as other factors. To address degradation, it is necessary to investigate microstructure changes after longduration annealing in air or in vacuum. In pursuit of high absorber efficiency, we should also consider cost and environmental issues. Solution-based methods can meet the requirement of low cost, however the coatings prepared by this method have a relatively low spectral selectivity compared with other techniques. The incorporation of a solution-based method with other techniques, such as CVD, evaporation, or sputtering may balance the cost and performance of the absorber.

In this article, we mainly focused on cermet-based spectrally-selective absorbers. State-ofthe-art cermet materials prepared through various methods, such as electroplating, anodizing, evaporation, CVD, sputtering and solution-based methods, were reviewed based on the different dielectric materials in cermet. Absorbers incorporating cermet coatings based on $\mathrm{Cr}_{2} \mathrm{O}_{3}, \mathrm{Al}_{2} \mathrm{O}_{3}, \mathrm{AlN}$, $\mathrm{SiO}_{2}$, and other materials were introduced one by one and their spectral characteristics were analyzed. The spectral properties of the cermets can be changed by varying the experimental parameters and film configurations to maximize the absorber efficiency.

\section{Acknowledgements}

This work is supported by "Concentrated Solar Thermoelectric Power (CSP)" under award number DE-EE0005806. 


\section{Notes and references}

1. P. M. Boffey, Science, 1970, 168, 1554-1559.

2. D. Abbott, P IEEE, 2010, 98, 42-66.

3. A. Shah, P. Torres, R. Tscharner, N. Wyrsch and H. Keppner, Science, 1999, 285, 692-698.

4. G. Masson, M. Latour, M. Rekinger, I.-T. Theologitis and M. Papouts, in European Photovoltaic Industry Association, ed. C. Winneker, 2013.

5. D. Mills, Sol Energy, 2004, 76, 19-31.

6. D. Kraemer, B. Poudel, H. P. Feng, J. C. Caylor, B. Yu, X. Yan, Y. Ma, X. W. Wang, D. Z. Wang, A. Muto, K. McEnaney, M. Chiesa, Z. F. Ren and G. Chen, Nat Mater, 2011, 10, 532-538.

7. F. Mauthner and W. Weiss, in Markets and Contribution to the Energy Supply 2011, Solar Heating \& Cooling Programme International Energy Agency, 2013.

8. N. Wang, L. Han, H. C. He, N. H. Park and K. Koumoto, Energ Environ Sci, 2011, 4, 3676-3679.

9. C. E. Kennedy, National Renewable Energy Laboratory, 2002.

10. G. A. Niklasson and C. G. Granqvist, J Mater Sci, 1983, 18, 3475-3534.

11. H. Tabor, in Transactions of the Conference on the use of Solar Energy, The Scientific Basis, October 31-November 1, Tucson, 1955.

12. P. Bermel, J. Lee, J. D. Joannopoulos, I. Celanovic and M. Soljacic, Annual Review of Heat Transfer, 2012, 14 .

13. K. McEnaney, in Department of Mechanical Engineering, Massachusetts Institute of Technology, 2010.

14. J. T. Gier and R. V. Dunkle, Transactions of the Conference on the Use of Solar Energy, The Scientific Basis, Tucson, October 31-November 1, 1955.

15. H. Tabor and I. T. Steinberger, J Sci Instrum, 1956, 33, 356-358.

16. H. Tabor, Sci Am, 1956, 195, 97-\&.

17. R. B. Pettit, R. R. Sowell and I. J. Hall, Sol Energ Mater, 1982, 7, 153-170.

18. D. P. Grimmer and R. K. Collier, Sol Energy, 1981, 26, 467-469.

19. C. P. Lampert, in Second Annual Conference on Absorber Surfaces for Solar Receivers, Gounder, CO, 1979.

20. G. E. Mcdonald, Sol Energy, 1975, 17, 119-122.

21. T. S. Sathiaraj, R. Thangaraj, H. Alsharbaty and O. P. Agnihotri, Thin Solid Films, 1991, 195, 33-42.

22. T. S. Sathiaraj, R. Thangaraj, H. Alsharbaty, M. Bhatnagar and O. P. Agnihotri, Thin Solid Films, 1990, 190, 241-254. 
23. H. G. Craighead and R. A. Buhrman, Appl Phys Lett, 1977, 31, 423-425.

24. H. C. Barshilia, N. Selvakumar, K. S. Rajam and A. Biswas, J Appl Phys, 2008, 103.

25. B. Orel, Z. C. Orel and I. Radoczy, Sol Energ Mater, 1988, 18, 97-107.

26. B. Orel, H. Spreizer, A. S. Vuk, M. Fir, D. Merlini, M. Vodlan and M. Kohl, Sol Energ Mat Sol C, 2007, 91, 108-119.

27. B. Orel, H. Spreizer, L. Slemenik Perše, M. Fir, A. Šurca Vuk, D. Merlini, M. Vodlan and M. Köhl, Sol Energ Mat Sol C, 2007, 91, 93-107.

28. C. A. Arancibia-Bulnes, C. A. Estrada and J. C. Ruiz-Suarez, J Phys D Appl Phys, 2000, 33, 24892496.

29. N. Selvakumar and H. C. Barshilia, Sol Energ Mat Sol C, 2012, 98, 1-23.

30. R. L. Champion and S. N. Laboratories, Proceedings of the Line-focus Solar Thermal Energy Technology Development: A Seminar for Industry, Albuquerque, New Mexico, September 9, 10, 11, 1980, National Technical Information Service, 1981.

31. R. B. Pettit and R. R. Sowell, J Vac Sci Technol, 1976, 13, 596-602.

32. J. Salmi, J. P. Bonino and R. S. Bes, J Mater Sci, 2000, 35, 1347-1351.

33. A. Andersson, O. Hunderi and C. G. Granqvist, J Appl Phys, 1980, 51, 754-764.

34. Q. C. Zhang and D. R. Mills, Appl Phys Lett, 1992, 60, 545-547.

35. G. A. Niklasson and C. G. Granqvist, Sol Energ Mater, 1983, 7, 501-510.

36. H. G. Craighead, R. E. Howard, J. E. Sweeney and R. A. Buhrman, Appl Phys Lett, 1981, 39, 29-31.

37. D. S. Gogova, Mater Lett, 1997, 30, 109-113.

38. B. O. Seraphin, Thin Solid Films, 1976, 39, 87-94.

39. V. Teixeira, E. Sousa, M. F. Costa, C. Nunes, L. Rosa, M. J. Carvalho, M. Collares-Pereira, E. Roman and J. Gago, Thin Solid Films, 2001, 392, 320-326.

40. J. C. C. Fan and S. A. Spura, Appl Phys Lett, 1977, 30, 511.

41. Q. C. Zhang and Y. G. Shen, Sol Energ Mat Sol C, 2004, 81, 25-37.

42. Q.-C. Zhang, Sol Energ Mat Sol C, 2000, 62, 63-74.

43. Z. Li, J. Zhao and L. Ren, Sol Energ Mat Sol C, 2012, 105, 90-95.

44. X. X. Wang, H. F. Li, X. B. Yu, X. L. Shi and J. F. Liu, Appl Phys Lett, 2012, 101.

45. I. T. Ritchie, S. K. Sharma, J. Valignat and J. Spitz, Sol Energ Mater, 1979, 2, 167-176.

46. C. Nunes, V. Teixeira, M. L. Prates, N. P. Barradas and A. D. Sequeira, Thin Solid Films, 2003, 442, 173-178.

47. Y. Yin, Y. Pan, L. X. Hang, D. R. McKenzie and M. M. M. Bilek, Thin Solid Films, 2009, 517, 1601-1606. 
48. W. Graf, F. Brucker, M. Köhl, T. Tröscher, V. Wittwer and L. Herlitze, J Non-Cryst Solids, 1997, 218, 380-387.

49. S. N. Kumar, L. K. Malhotra and K. L. Chopra, Sol Energ Mater, 1983, 7, 439-452.

50. T. Moller and D. Honicke, Sol Energ Mat Sol C, 1998, 54, 397-403.

51. T. Boström, E. Wäckelgård and G. Westin, Sol Energy, 2003, 74, 497-503.

52. T. Boström, E. Wäckelgård and G. Westin, Sol Energ Mat Sol C, 2004, 84, 183-191.

53. T. Boström, S. Valizadeh, J. Lu, J. Jensen, G. Westin and E. Wäckelgård, J Non-Cryst Solids, 2011, 357, 1370-1375.

54. B. Chen, D. F. Yang, P. A. Charpentier and S. Nikumb, Sol Energ Mat Sol C, 2008, 92, 1025-1029.

55. H. C. Barshilia, P. Kumar, K. S. Rajam and A. Biswas, in Sol Energ Mat Sol C, 2011, 95. 1707-1715.

56. D. Xinkang, W. Cong, W. Tianmin, Z. Long, C. Buliang and R. Ning, Thin Solid Films, 2008, 516, 3971-3977.

57. J. Cheng, C. Wang, W. Wang, X. Du, Y. Liu, Y. Xue, T. Wang and B. Chen, Sol Energ Mat Sol C, 2013, 109, 204-208.

58. A. Antonaia, A. Castaldo, M. L. Addonizio and S. Esposito, Sol Energ Mat Sol C, 2010, 94, 16041611.

59. Z. Y. Nuru, C. J. Arendse, R. Nemutudi, O. Nemraoui and M. Maaza, Physica B, 2012, 407, 16341637.

60. Q.-C. Zhang, Journal of Vacuum Science \& Technology A: Vacuum, Surfaces, and Films, 1997, 15, 2842-2846.

61. Q.-C. Zhang, Sol Energ Mat Sol C, 1998, 52, 95-106.

62. Q.-C. Zhang, in Proceedings of ISES World Congress 2007 (Vol. I - Vol. V), eds. D. Y. Goswami and Y. Zhao, Springer Berlin Heidelberg, 2009, pp. 1847-1853.

63. Q. C. Zhang, J Phys D Appl Phys, 1998, 31, 355-362.

64. Q. C. Zhang, J Phys D Appl Phys, 2001, 34, 3113-3120.

65. Q. C. Zhang, Proceedings of Ises Solar World Congress 2007: Solar Energy and Human Settlement, Vols I-V, 2007, 1847-1853.

66. Q.-C. Zhang, K. Zhao, B.-C. Zhang, L.-F. Wang, Z.-L. Shen, D.-Q. Lu, D.-L. Xie, Z.-J. Zhou and B.-F. Li, AVS, 1998, pp. 628-632.

67. D. A. G. Bruggeman, Ann. Phys., 1935, 24, 636-647.

68. S. X. Zhao and E. Wäckelgård, Sol Energ Mat Sol C, 2006, 90, 1861-1874.

69. M. Nishimura and T. Ishiguro, Jpn J Appl Phys, 2004, 43, 757-761.

70. J. A. Wang, B. C. Wei, Q. R. Wei and D. J. Li, Phys Status Solidi A, 2011, 208, 664-667.

71. S. Esposito, A. Antonaia, M. L. Addonizio and S. Aprea, Thin Solid Films, 2009, 517, 6000-6006. 
72. F. Garnich and E. Sailer, Sol Energ Mater, 1990, 20, 81-89.

73. M. Okuyama, K. Furusawa and Y. Hamakawa, Sol Energy, 1979, 22, 479-482.

74. W. Brünger, Vacuum, 1980, 30, 125-127.

75. M. Farooq, A. A. Green and M. G. Hutchins, Sol Energ Mat Sol C, 1998, 54, 67-73.

76. P. K. Gogna and K. L. Chopra, Sol Energy, 1980, 23, 405-408.

77. O. P. Agnihotri, B. K. Gupta, A. K. Agarwal and V. P. Bhatnagar, Thin Solid Films, 1983, 109, 193200.

78. Q.-C. Zhang, M. S. Hadavi, K.-D. Lee and Y. G. Shen, Journal of Physics D: Applied Physics, 2003, 36, 723 .

79. R. C. Juang, Y. C. Yeh, B. H. Chang, W. C. Chen and T. W. Chung, Thin Solid Films, 2010, 518, 5501-5504.

80. N. Selvakumar, N. T. Manikandanath, A. Biswas and H. C. Barshilia, Sol Energ Mat Sol C, 2012, 102, 86-92. 